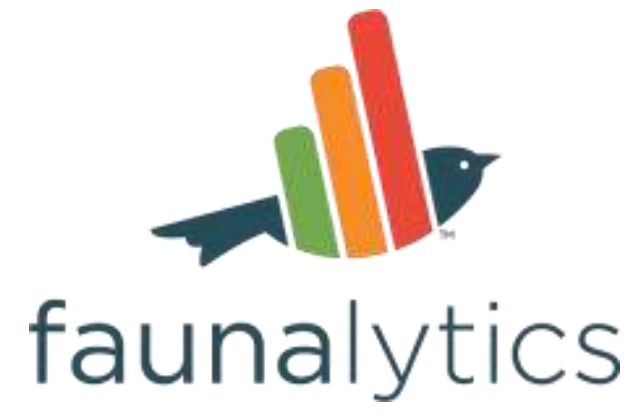

\title{
Impact of Corporate Commitments on Public Attitudes
}

May 2019

Authors: Jo Anderson \& Alison Lenton

Faunalytics 


\section{faunalytics}

\section{Contents}

(Click to go to page)

\section{Background}

Project Overview

\section{Key Findings}

\section{Team}

\section{Thematic Analysis}

Method

Coding and Analysis

\section{Results}

Overall Results

Intended Purchase Or Consumption Behavior

Attitudes About Animal Welfare

Critical Of Welfare Implications

Enthusiastic About Welfare Implications

Calls For More Welfare Improvements

Apathy: Who Cares?

Complacency: Everything Is Fine Now

Attitudes Toward Corporations Making Cage-Free Commitments

Overall Sentiment

Critical Of Timeline

Skeptical About Follow-Through

Attitudes Toward Animal Advocates

The Human Implications Of Cage-Free Egg Reform

Higher Cost

Aesthetics

Health And Safety

Restriction Of Consumer Choice

Cage-Free Hurts Farmers

Additional Themes

Wants More Change From Corporation In Other Areas

Information-Sharing

Excluded Themes

Limitations Of Results 


\section{faunalytics}

Representation Of Corporations And General Public

Overrepresentation Of Animal Advocates?

\section{Comparative Analysis: Cage-Free Vs. Comparison Article Comments}

Research Questions

Emotional Reactions

Questions

Swearing And Exclamations

Exploratory Analyses: Other Differences Between The Cage-Free And Comparison Articles

They Versus I

Money

Causation

Death, Anger, Sadness, And Other Non-Significant Differences

\section{Conclusions}

Advocates Should Continue To Emphasize Corporate Lobbying

Corporations Should Not Fear Response To Animal Welfare Improvements

Public Interest Pertaining To Animal Welfare Reform

Public Understanding Of Animal Advocates' Role In Reform

Public Understanding Of Issues

\section{Supplementary Materials}

Detailed Method

Pre-Registration

Data Set Inclusion Criteria

Data Collection

Thematic Content Coding

Coding Scheme 


\section{faunalytics}

\section{Background}

In recent years, corporate lobbying efforts have played an increasing role in animal advocacy. They have been successful in bringing about dozens of commitments to use or provide cage-free eggs and enact other welfare improvements. These changes have been attributed by the companies themselves to pressure from animal advocacy groups (Open Philanthropy, 2017).

This research project addresses a question that arises from these lobbying efforts: What impact do these corporate commitments to switching to cage-free eggs have on public attitudes?

More specifically, is there evidence of impact on:

1. Intended behavior,

2. Attitudes about animal welfare,

3. Attitudes about the corporation, or

4. Attitudes about animal advocates/advocacy?

Public reaction is directly important to the extent that it influences consumer behavior-for instance, by increasing or decreasing egg sales_or influences corporations' willingness to make additional welfare improvements. It may also be indirectly important if it influences attitudes toward animal advocates or advocacy organizations.

\section{Project Overview}

To assess public reaction, we analyzed a naturalistic dataset of responses to announcements of restaurant corporations' cage-free egg commitments on social media. This kind of dataset naturally weights itself to overrepresent larger, more visible corporations (e.g., McDonald's) and comments from more outspoken, motivated people. This means that it is not representative of the full population, but it is more representative of the kind of public discourse that occurs when these announcements are made. There are pros and cons to either approach, but this one allows natural responses to float to the surface without the research process itself influencing the results.

The comments were analyzed in two ways. First, a team of trained researchers read them and described a set of themes that emerged. This process allowed us to examine the range and relative frequency of themes. Second, comments from cage-free articles were compared against comments from a set of comparison articles on other topics using an automated text analysis. This analysis provides a benchmark against which frequencies of various themes can be interpreted-for instance, is the level of negativity in response to cage-free announcements higher or lower than we might expect on an average article?

\section{Key Findings}

1. Comments were more positive on average than for comparable social-media articles on other topics. Apathy, criticism, and enthusiasm in response to cage-free announcements by restaurant and fast-food corporations were all common, but any article 


\section{faunalytics}

will garner both positive and negative reactions. Results showed that the cage-free announcements had a higher proportion of positive reactions and a lower proportion of negative ones compared with other articles.

2. Most criticisms focused on the long transition timeline or said the change does not go far enough-few people criticized the corporation for making the move. Criticisms of the timeline were the most common theme in the dataset, followed by comments critical of the welfare implications of cage-free eggs. Those who were critical of the move itself were most often concerned about the potentially higher cost of cage-free eggs. Overall, this response to corporate animal welfare commitments is very encouraging.

3. Neither criticism nor enthusiasm about animal welfare reform translated into behavior. We had expected that we might see people over-claiming that they would increase or decrease their purchase behavior in response to the cage-free commitment. As it turned out, neither type of claim was common. This study provides tentative evidence that critical responses to animal welfare reform are unlikely to harm a corporation's bottom line, but also that enthusiastic responses are unlikely to help it. Even in a social media context where over-claiming would be both easy to do and impossible to disprove, most people did not claim that they would change their behavior. However, to test impact directly, studies would need to examine real purchases of products advertised as cagefree in the context of potentially higher prices.

4. The frequency of apathetic responses suggests that advocates should continue to emphasize corporate lobbying efforts. Apathy (largely seen in jokes and dismissive comments) suggests that many members of the general public do not care one way or the other about these changes. While disheartening, frequent apathy provides empirical support for continuing to lobby corporations over individuals. Apathetic individuals are unlikely to resist further corporate lobbying efforts (or subsequent improvements to animal welfare) and would provide poor targets for direct intervention.

5. Complacency was rare. This common concern about incremental change was somewhat rejected by this study, in that almost no one made comments suggesting that these welfare reforms are sufficient or that no more action is needed; however, this may be because it did not come to mind.

6. Animal advocates appear to be relatively invisible in these reforms, and that is probably a good thing. Only a few commenters referred to animal advocates, advocacy groups, or vegans in their responses to the articles. Most of those few references were negative, and they tended to occur about articles that explicitly referred to advocacy groups or in response to other commenters with a clear advocacy agenda. This suggests that, as long as the media doesn't play up advocates' role in obtaining corporate commitments, it doesn't come to mind for most people. Given that-when it did come to mind - the most common response was negative, we consider this a good thing and something to aim for. 


\section{faunalytics}

7. Concerns about the restriction of consumer choice or the transition hurting farmers were vanishingly rare. We looked specifically for these concerns because they are brought up in some debates about corporate campaigns, but almost no one in the general public commented about these issues. Each of these themes appeared only once in our dataset.

8. Few corporations had announced their cage-free commitments on their Facebook pages. Only 10 out of 75 restaurant corporations listed on advocacy websites as having made the commitment announced their commitment on Facebook. We suspect that many corporations may have been concerned about public reaction, but the results of this study may reassure them about future commitments. Making a public commitment is a wellknown way of ensuring follow-through, so we hope that these results can be used to encourage more openness in the future.

\section{Team}

This research project was the collective effort of many Faunalytics staff and volunteers. The Faunalytics research team of Jo Anderson, Julia Dauksza, and Che Green extend our thanks to the following volunteers: Lindsay Frederick for many hours spent coding comments, Alison Lenton for conducting the comparative text analysis, Justin Portela for finding the posts to include in the dataset, Paul Fornia for automating our data download process, and Kim Agricola for proofreading this report. We also thank Elyse Shuk and Shiva Pauer for their assistance, as well as the additional volunteers and members of other organizations who provided ideas and feedback at various stages of the design process. This project was a large, intensely collaborative effort. 


\section{faunalytics}

\section{Thematic Analysis}

\section{Method}

Throughout the report, example comments are provided verbatim, so please excuse spelling and grammar errors, which were retained from the original versions. Some comments also include swear words.

To understand public reaction to corporate cage-free egg commitments, we looked at comments on public Facebook posts announcing a commitment. Some of these announcements were made by the corporations themselves on their own Facebook pages. The rest were selected as a representative cross-section of news reports.

The thematic analysis below covers 1,617 comments pertaining to 22 corporations. The comments were drawn from 10 Facebook announcements by corporations and 53 news stories posted publicly to social media. For more details on the full set of comments, see the Supplementary Materials section.

\section{Coding and Analysis}

Coding refers to the process of reading comments and determining the themes they express. It is a way of quantifying open-ended data so that comparisons can be made. The coding process involved two research assistants who coded the comments. They were trained on the set of categories (coding scheme) and they attained over $80 \%$ agreement in the codes they chose. This was the standard we were striving for, per the recommendation of McHugh, 2012.

Most of the themes were chosen and pre-registered before the researchers looked at the data (deductive codes), based on common questions or theories about the impact of corporate commitments to cage-free egg reform. For instance, does it cause people to feel more or less positive toward the corporation? Are people concerned about increased costs?

Some additional categories were added to the coding scheme during the coding process, based on recurring themes that the coders observed in the comments (inductive codes). Most of these were less relevant to animal advocates' questions, but some provide useful information. For instance, coders noted a theme of people requesting corporations make non-animal-related changes, like avoiding preservatives or high fructose corn syrup.

For full details about the coding process and coding scheme, please see the Supplementary Materials section.

\section{Results}

We describe the themes that emerged from a qualitative analysis of the comments in order of their frequency. In the accompanying graphs, we show not just the frequency of each theme, but also the number of "likes" that comments with that theme received. (By "likes" we mean 


\section{faunalytics}

Facebook's thumbs-up reaction or love/heart reaction—either of these positive responses was considered a "like.")

In our presentation of the numbers below, bear in mind that 1,617 comments were coded overall, and that a wide variety of themes emerged, so the proportion of comments on any one theme is typically low. For this reason, we have provided the number of comments per theme and used graphs to show the relative proportion of similar themes, rather than percentages.

\section{Overall Results}

Figure 1 shows the relative proportion of comments and likes on each theme related to cage-free egg reform. 


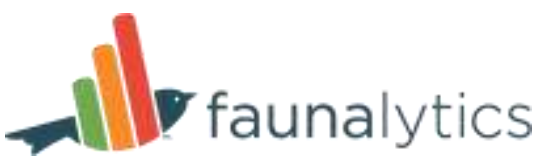

Figure 1. Frequency Of Cage-Free Egg Themes.

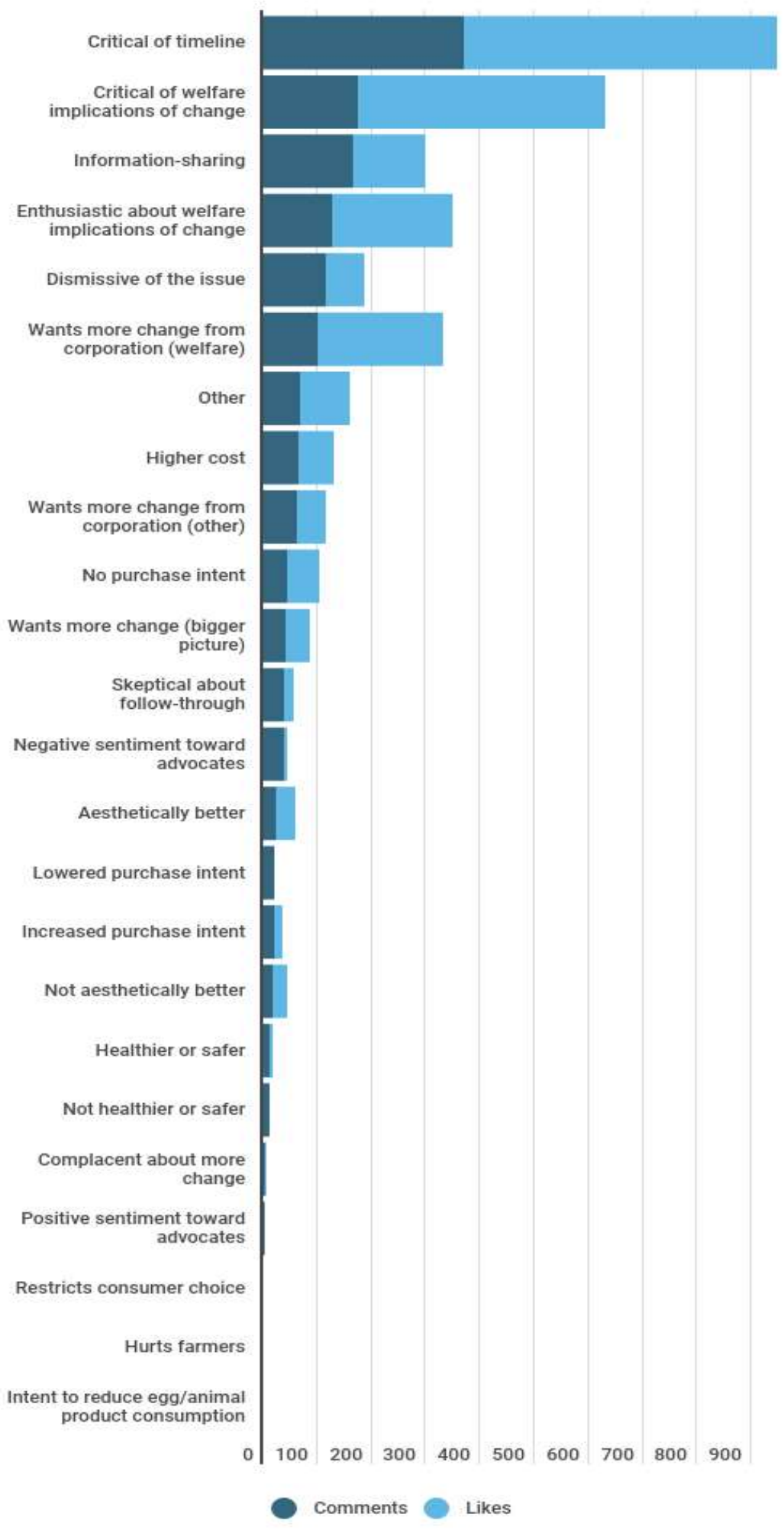




\section{faunalytics}

The next sections present the results grouped by topic so that the frequency of comments on similar issues can be compared.

\section{Intended Purchase Or Consumption Behavior}

Purchase intent was one of our key research questions in this study: how would a corporation's announcement of transitioning to cage-free eggs affect the public's intended behavior? Figure 2 shows comments related to this question.

Figure 2. Comments About Intended Purchase And Consumption Behavior.

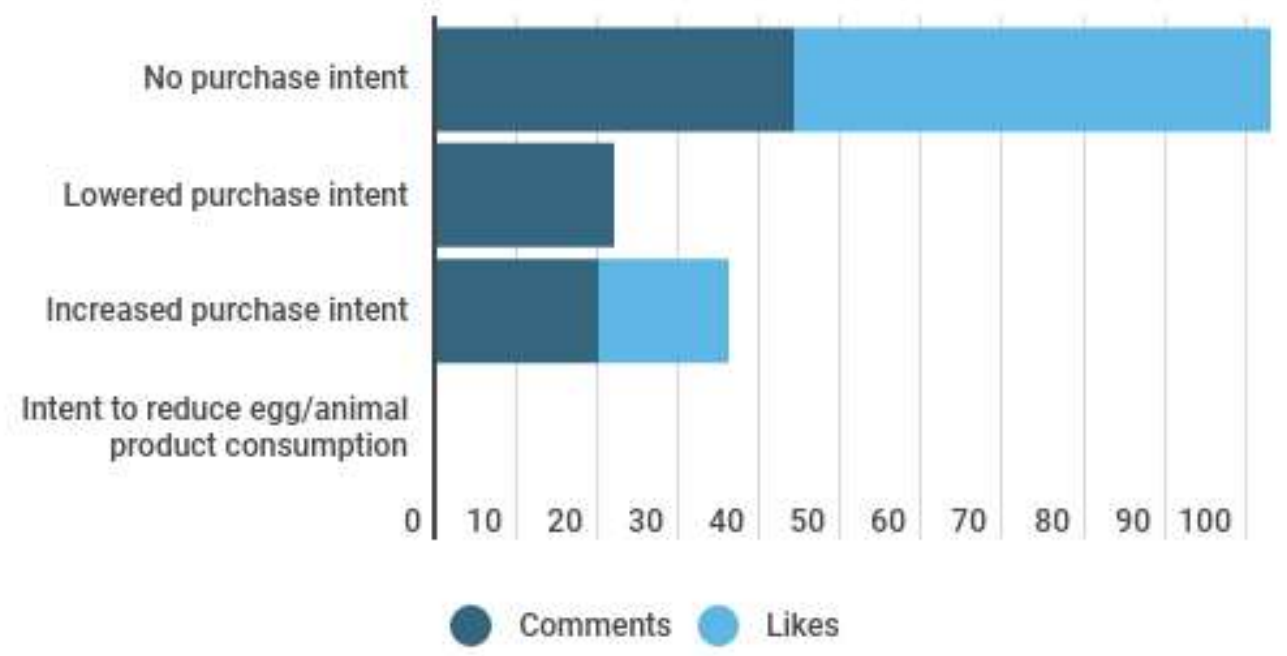

Note. This graph shows a subset of the same results shown in Figure 1.

We had expected to see people claiming they would either increase their purchase behavior in support of the welfare improvements or decrease their purchase behavior if they expected higher costs or had other concerns. Interestingly, neither type of comment was common: 22 comments (with 0 likes) indicated lowered intent and 20 comments (with 16 likes) indicated increased intent.

Instead, the most frequent comments related to purchase intent were ones indicating no intent (Figure 3): that the commenter had never eaten at this restaurant, and never would (44 comments, 59 likes). Though negative, this type of commenter is neither a current consumer nor a probable future consumer, so their opinions are not of high importance. 


\section{faunalytics}

This study provides initial evidence that changes in purchase intent-in either direction-are fairly unlikely. Comments suggesting a change in purchase behavior made up less than $3 \%$ of all comments. They also made up just under half of the comments that explicitly referred to purchase intent.

A study of actual purchase behavior would provide better data, of course, but this finding should allay corporations' concerns about people abandoning them in droves. Dissatisfaction with a corporation's change was common, as described in the next section, but few people claimed that they would stop eating there because of the change.
Figure 3. Comment Examples: No Purchase Intent.

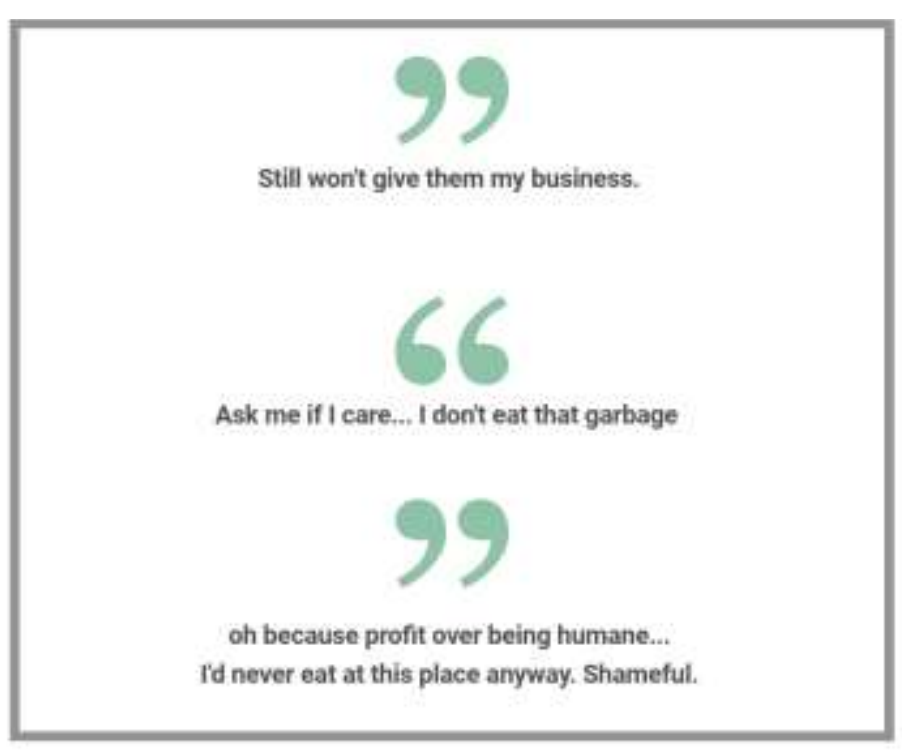

We were also interested in whether the discussion about cage-free eggs might spur people to reduce their consumption of eggs or animal products, perhaps by inspiring them to look further into issues of hen welfare. We included a deductive category in the coding scheme for this, but found that none of the commenters expressed an intention to reduce their overall consumption of eggs or animal products. This finding suggests that this type of effect is unlikely.

\section{Attitudes About Animal Welfare}

Another key research question was how a corporation's announcement of transitioning to cagefree eggs would affect the public's attitudes about animal welfare. Announcements like this put the welfare of factory-farmed hens in the spotlight in a way that doesn't often happen. So what is the reaction when hen welfare is brought to light? Does the public care? Do they view cage-free egg reform as a positive step or not enough action? Figure 4 shows comments related to attitudes about animal welfare. 


\section{faunalytics}

Figure 4. Comments About Animal Welfare Implications.

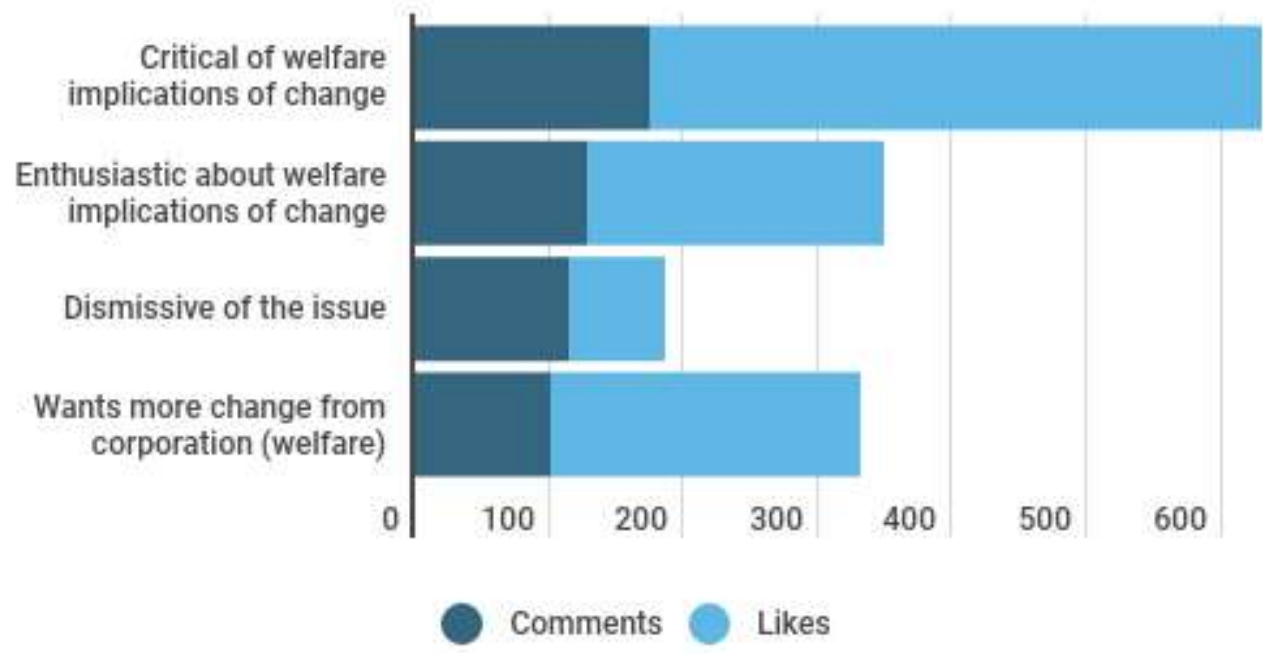

Note. This graph shows a subset of the same results shown in Figure 1.

\section{Critical Of Welfare Implications}

Welfare-based criticisms of cage-free commitments were common (Figure 5). Overall, 175 comments criticized the implications of a cage-free transition for hen welfare, and these received the most likes of any type of comment (455 likes, or 2.6 likes per comment on average). Some of these comments suggested that the company should be aiming for other types of higher-welfare eggs (e.g., free range or pastureraised). The prevalence of this theme suggests that a significant group of people do not accept the premise of cage-free campaigns improving welfare for hens.
Figure 5. Comment Examples: Critical Of Welfare Implications.

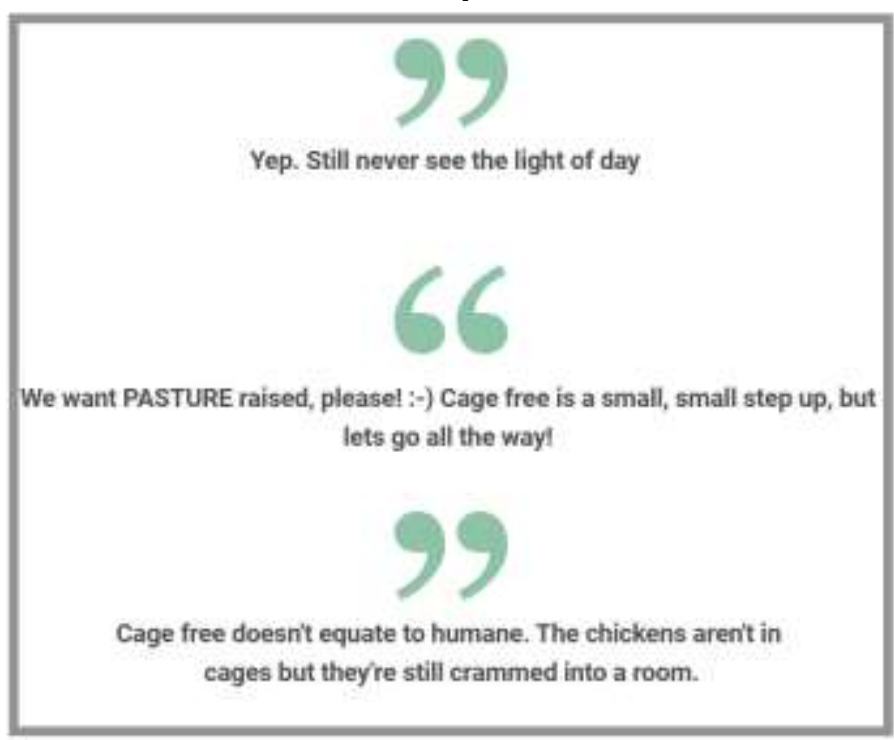




\section{faunalytics}

\section{Enthusiastic About Welfare Implications}

On the other hand, positivity about welfare improvements was also quite common (127 comments with 221 likes), as shown in the examples (Figure 6).

\section{Calls For More Welfare Improvements}

Comments expressing a desire for further welfare improvements from the corporation announcing a transition (Figure 7) were slightly less common than criticism or enthusiasm about the transition itself. About half of them were paired with one sentiment or the other.

As shown in Figure 8 below, 34 (34\%) of these comments were paired with criticisms of the welfare implications of cage-free eggs. These comments suggest an attitude of "this isn't enough-do more."

Another 15 (15\%) of these comments paired a request for more welfare improvements with positive reinforcement of current efforts. This approach is more akin to saying "good work-keep going."
Figure 6. Comment Examples: Enthusiastic About Welfare Implications.

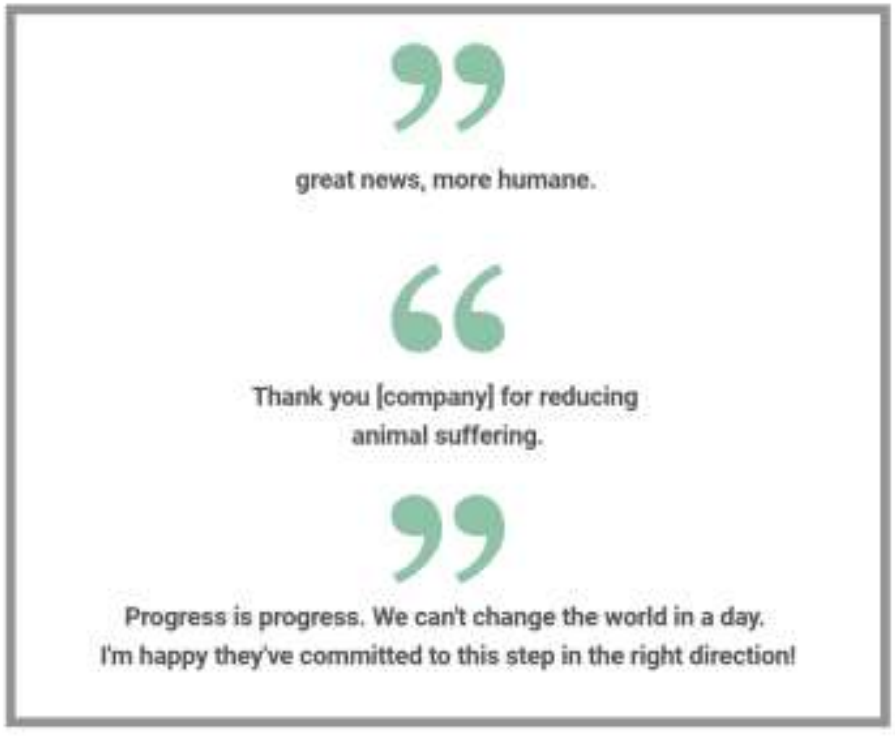

Figure 7. Comment Examples: Calls For More Welfare Improvements.

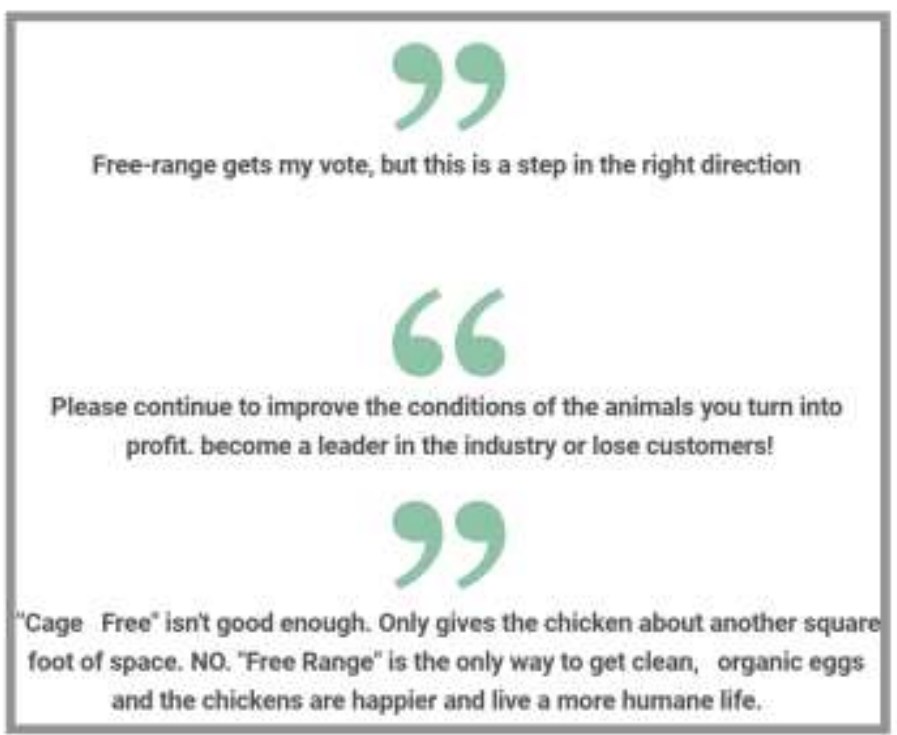




\section{faunalytics}

\section{Figure 8. Combination Of Criticism/Enthusiasm And Calls For More Welfare Improvements.}

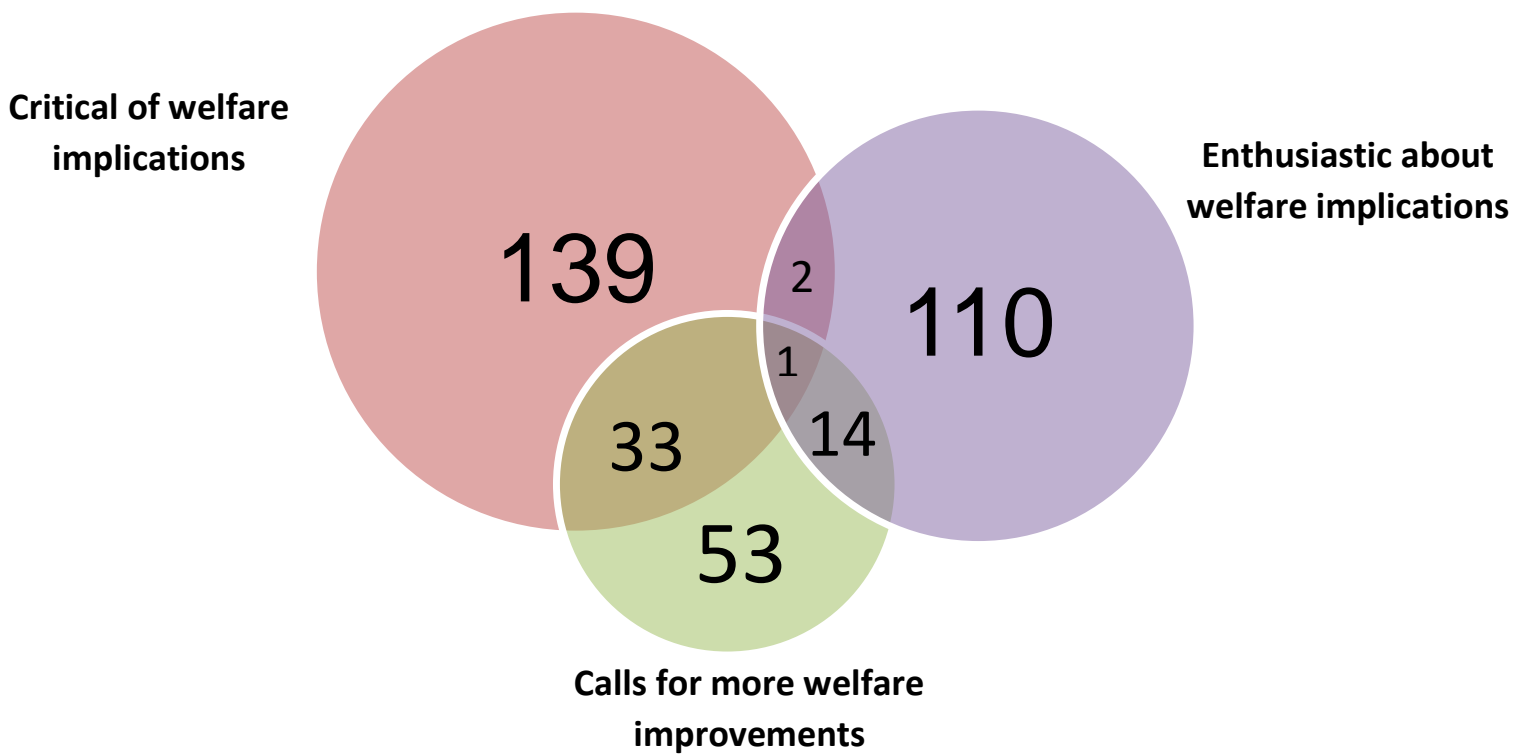

Note. Diagram is not to scale.

It is worth noting that calls for additional welfare improvements were focused mostly on layer hens. This suggests that-for the minority of people who think longer-term at all-incremental animal welfare reform brings to mind additional changes for the affected group of animals (layer hens, in this case), rather than reform for other animals (e.g., broiler chickens, pigs).

Advocacy groups that crowd-source lobbying efforts may want to consider this tendency when deciding how to present new calls for action to their members. Sometimes switching lobbying efforts from one group of animals to another will make sense for practical reasons (e.g., allowing time between requests, targeting more tractable issues), but those reasons may not be obvious to members. Considering members' expectations and framing calls to action accordingly will benefit coordination and collaboration. 


\section{faunalytics}

Finally, some comments called for bigger-picture change (42 comments with 45 likes), as examples in Figure 9 show. Many were calls for action directed at other corporations, government, or society at large. As a result, they seem more like an expression of the commenter's desires than an actual request for change, as the target corporation would be powerless to make most of them.

Because these comments can't function as an actual call to action for the target corporation, the prevalence of this theme suggests that commenters want to influence others on social media with their opinions and/or present themselves in a positive light.

\section{Apathy: Who Cares?}

Sadly (but perhaps unsurprisingly), comments dismissing the importance of the issue (hen welfare, transitioning to higher-welfare systems) were also frequent. We coded 114 comments (with 73 likes) as dismissive, but this estimate is probably low.

Comments that were excluded from analysis for being "insubstantial or uninterpretable" are described in the Excluded Themes section below. A sizeable proportion of those comments were ambiguous-coders could not reliably tell whether they were serious or tongue-in-cheek. If we interpret some of those comments as dismissive because they seem to joke about the issue, the prevalence of this theme could more than double.
Figure 9. Comment Examples: Demand For More Change (Bigger Picture).

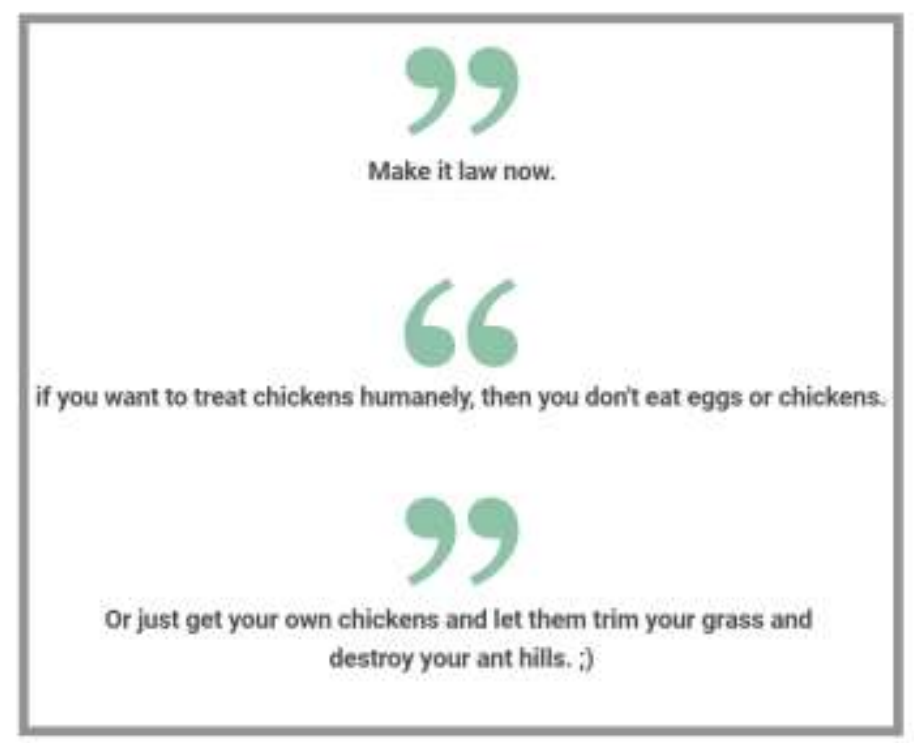

Figure 10. Comment Examples: Complacency And Dismissiveness.

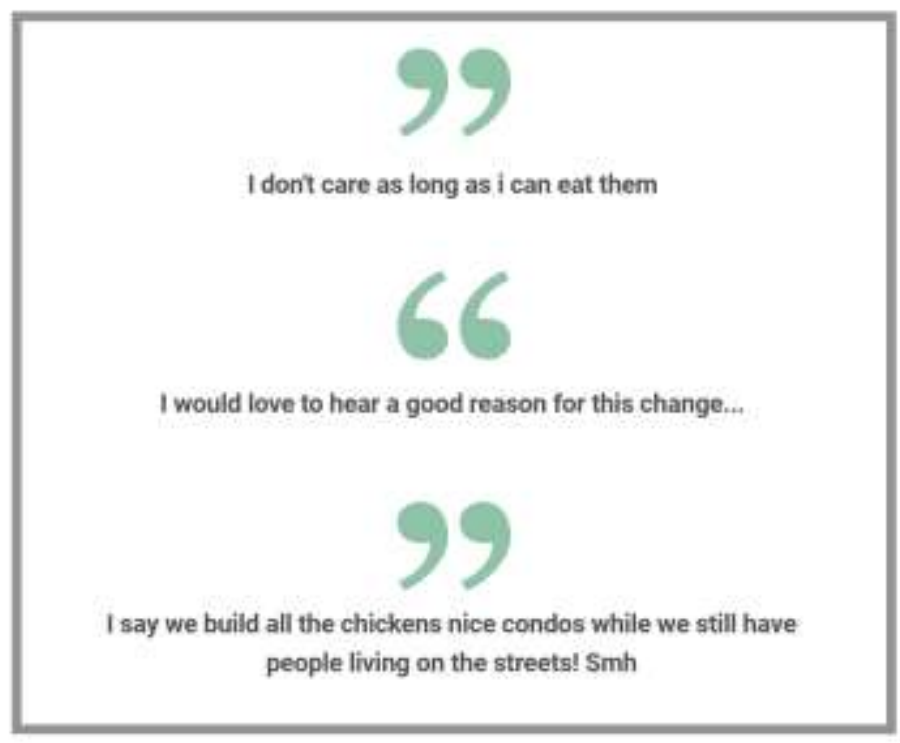




\section{faunalytics}

That said, apathy in the general public is an excellent reason to continue emphasizing lobbying efforts aimed at corporations rather than individuals. As described above, very few people indicated lower purchase intent due to the transition to cage-free eggs. Thus, while they might not choose to prioritize the issue, their dismissiveness toward it does not appear to drive behavioral change. In this case, that is a positive result.

\section{Complacency: Everything Is Fine Now}

Very few people (3 comments with 2 likes) explicitly said that the transition to cage-free eggs was enough and now the welfare fight is done. While this is good news, implied complacency may be a larger issue. Earlier in this text, we reported that 127 comments were enthusiastic about the welfare implications of the switch to cage-free eggs. Of those comments, only $15(12 \%)$ also called for further action. These commenters appear to be satisfied with this level of welfare improvement and are not pushing for more. However, this sort of passive complacency does not suggest that these positive responders would resist further lobbying efforts. On the contrary, they might be equally enthusiastic about additional reforms.

\section{Attitudes Toward Corporations Making Cage-Free Commitments}

Our final research question was how the public would react to a corporation's choice to transition to cage-free eggs. This is important to animal advocates because it is important to the corporations themselves.

On this subject, it is worth noting that only 10 of the 75 restaurants on our full list had announced their cage-free commitments on their Facebook pages, as described in the Supplementary Materials section. This may suggest that most corporations preferred to keep their commitments out of the public eye-perhaps over concern about public reaction.

The results of this study should reassure corporations about future commitments. As noted in the Key Findings section, reactions to these commitments were more positive than reactions to a comparison group of social media articles on other topics. Also, criticisms, though common, were rarely about the corporation's choice to transition to cage-free eggs. The overall sentiment was quite supportive of animal welfare reform. 


\section{faunalytics}

Figure 11. Comments About Corporate Cage-Free Commitments.

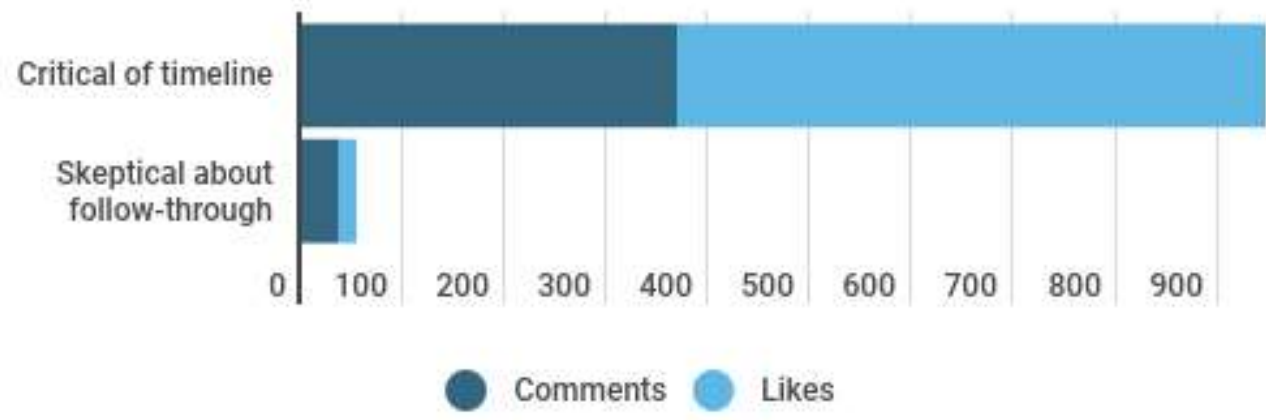

Note. This graph shows a subset of the same results shown in Figure 1.

\section{Overall Sentiment}

Before categorizing each comment by theme, coders decided whether each one expressed or implied any sentiment toward the corporation mentioned in the post. These sentiments did not necessarily have anything to do with cage-free egg reform, however-we discovered that many people took the opportunity to express their opinions of these corporations regardless of relevance. These ratings should not be viewed as indicative of how people respond to corporations' cage-free commitments.

Of 1,617 comments, coders rated 555 on this sentiment scale. The scale had five points, from very negative (1) to very positive (5), with a midpoint of neutral or mixed (3). Half-point responses in the graph occurred when the two coders gave different ratings, which were averaged together.

Positive and negative sentiment toward corporations was evenly split. The average rating was 3.0, exactly at the scale midpoint. Overall, 281 comments (with 279 likes) expressed negative sentiment toward the corporation, and 263 comments (with 133 likes) expressed positive sentiment.

Many of the people expressing negative sentiment (128 comments) made complaints that were unrelated to the cage-free egg reform (e.g., disparaging the restaurant's food quality), and many of the others (73 comments) were related to the two complaints outlined below, about the timeline or follow-through.

On the other hand, the majority of the people expressing positive sentiment (149 comments) were simply positive (e.g., "Thanks [company]!"); their comments did not reference any other theme.

Overall, this sentiment analysis points toward a positive interpretation of public reaction to corporate animal welfare reform. Most negative comments were not made in response to the corporation's commitment to change, but most positive comments can be taken at face value as simple goodwill toward the corporation's commitment. 


\section{faunalytics}

\section{Critical Of Timeline}

The most common theme that emerged from the entire analysis was criticism of corporations' timeline for their cage-free transition (369 comments with 578 likes). Many of these timelines were ten years.

Almost one in four comments (23\%) mentioned the timeline, and these comments were liked at one of the highest rates in the study: an average of 1.6 likes per comment. In particular, jokes and sarcasm about the timeline were common.

This theme suggests that many people either do not understand or reject explanations about the need to transition a supply chain from battery cage eggs to cage-free eggs.

\section{Skeptical About Follow-Through}

Despite the degree of negativity about the timeline, few people were overtly skeptical about corporations' likelihood of following through (37 comments with 18 likes). The relatively low number of comments on this theme and the multitude of comments on the length of the timeline both suggest a lack of understanding of the need to convert a supply chain to cage-free eggs. Full conversion is effortful and requires a corporation to ensure that many different suppliers have either converted or been replaced. It might be more reasonable to accept that the process could be time-consuming but also suspect that corporations might not follow through entirely. However, comments followed the opposite pattern, suggesting that the general public is
Figure 12. Comment Examples: Critical Of Timeline.

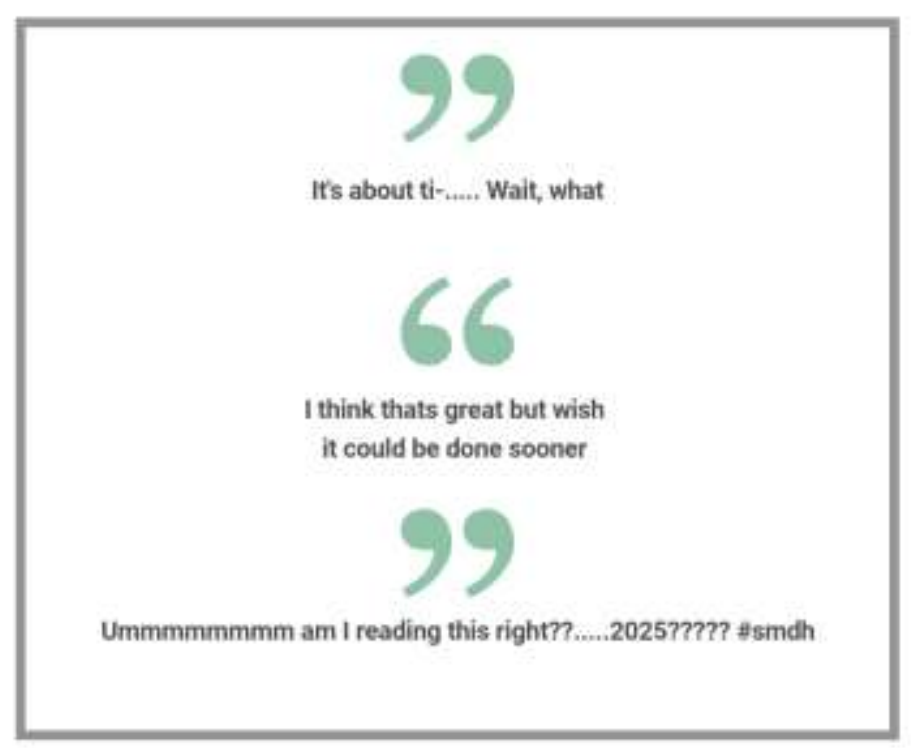

Figure 13. Comment Examples: Skeptical About Follow-Through.

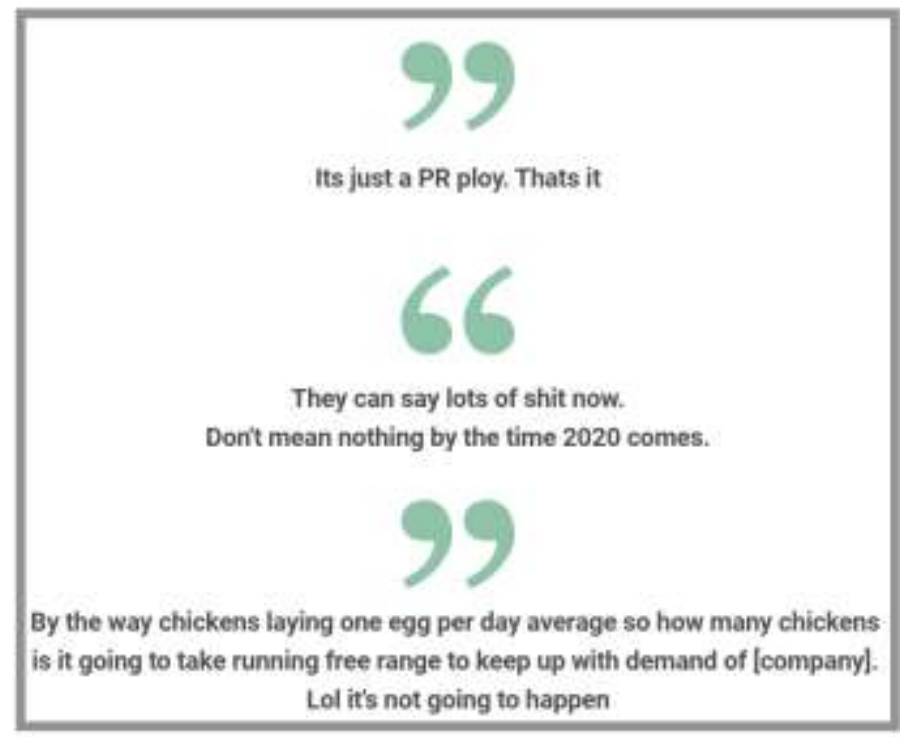




\section{faunalytics}

somewhat out of sync with advocates' concerns, which focus on follow-through (e.g., Bloomberg, 3/8/2019; EggTrack).

\section{Attitudes Toward Animal Advocates}

Our final research question was whether the public would comment on the role of animal advocates in bringing about corporate animal welfare commitments, either positively or negatively. As it turned out, very few of them did, so we have only an overall sentiment rating for this theme from the 43 comments that expressed or implied some sort of sentiment toward animal advocates. These were rated on the same 5-point scale ranging from very negative (1) to very positive (5) as attitudes toward the corporations.

Most people who commented on animal advocates or advocacy groups did so negatively, but this still amounted to only 37 comments (with 6 likes) of 1,617 total (3\%). The average rating across the 43 comments was 1.9 , close to somewhat negative.

Negative comments toward animal advocates included some that were specifically directed at the Humane Society of the United States (HSUS), because a few of the articles explicitly mentioned partnerships with the HSUS. There is not enough evidence in this study to say for sure, but calling attention to the role of advocates and lobbyists in these reforms may be detrimental to the cause.

\section{The Human Implications Of Cage-Free Egg Reform}

\section{Higher Cost}

Concern about higher egg costs associated with going cage-free was relatively common, accounting for 66 comments and 130 likes. A study of purchase behavior is needed to examine the impact when costs reach the consumer, but this suggests that at least a subset of consumers will be on the lookout for price hikes.
Figure 14. Comment Examples: Higher Cost.

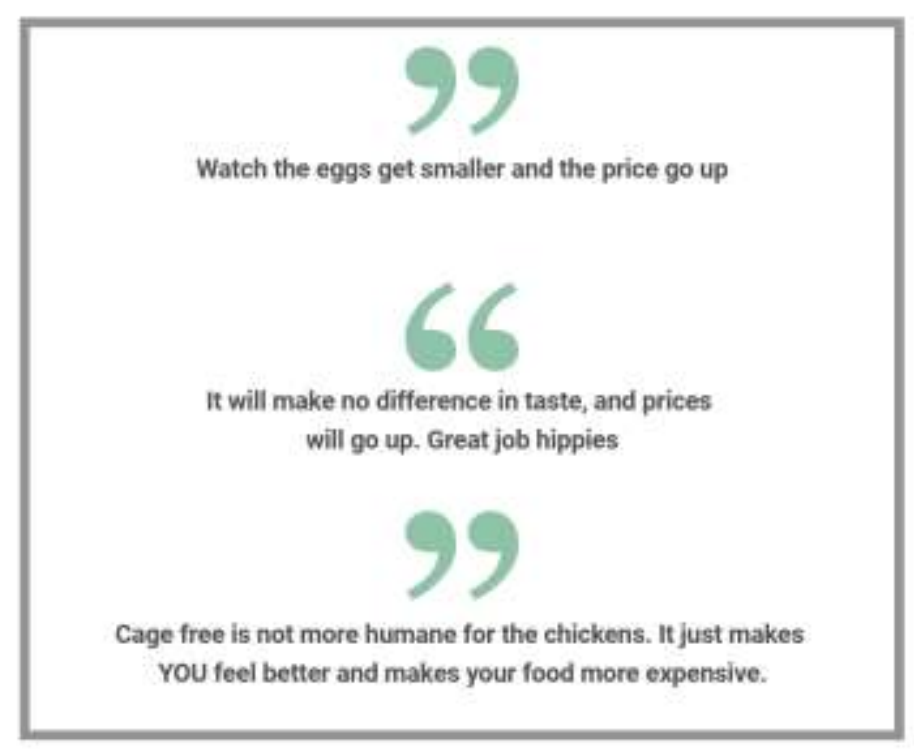




\section{faunalytics}

\section{Aesthetics}

A few people (24 comments, 34 likes) claimed that there are aesthetic benefits (taste, texture, look) to cagefree eggs. This belief was more common than the belief that there is no aesthetic difference (17 comments, 26 likes).

\section{Health And Safety}

Health and safety concerns about cage-free versus caged eggs (in either direction) do not appear to be top of mind for the general public. Only 11 comments (with 7 likes) claimed that cage-free eggs are healthier or safer than caged eggs, and another 11 comments (with 2 likes) claimed that they are not. However, this does not mean that the public wouldn't respond well to messaging about health and safety if advocates wanted to use it to garner support-they might or might not.

\section{Restriction Of Consumer Choice}

We included a coding category for comments about this kind of change restricting consumer choice, which is sometimes mentioned in debates about corporate campaigns: that the free market should be allowed to decide what is important and what isn't, rather than lobbyists.
Figure 15. Comment Examples: Aesthetics.

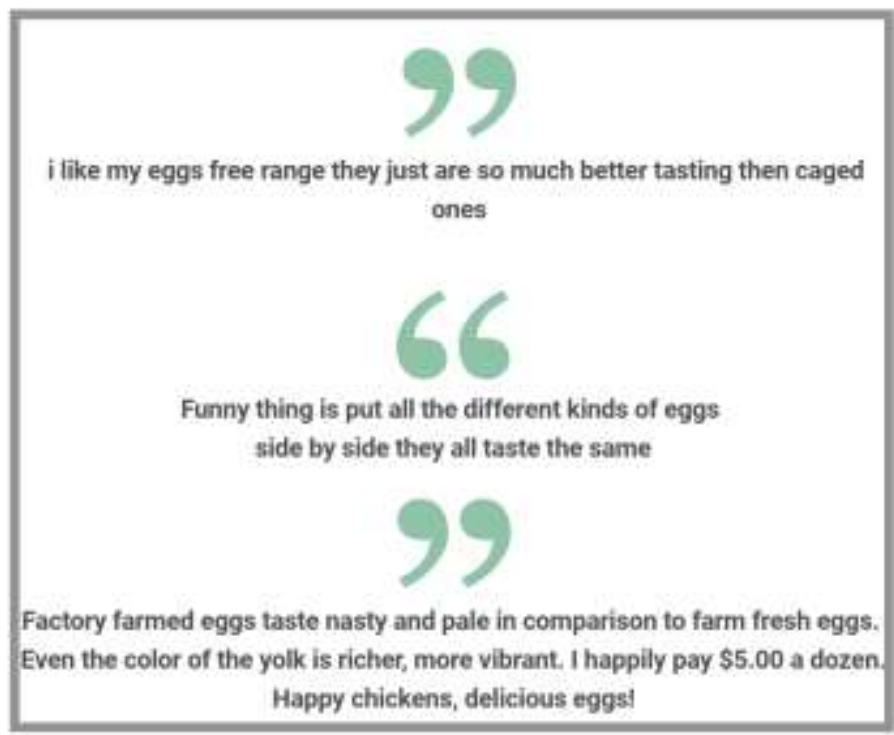

Figure 16. Comment Examples: Health And Safety.

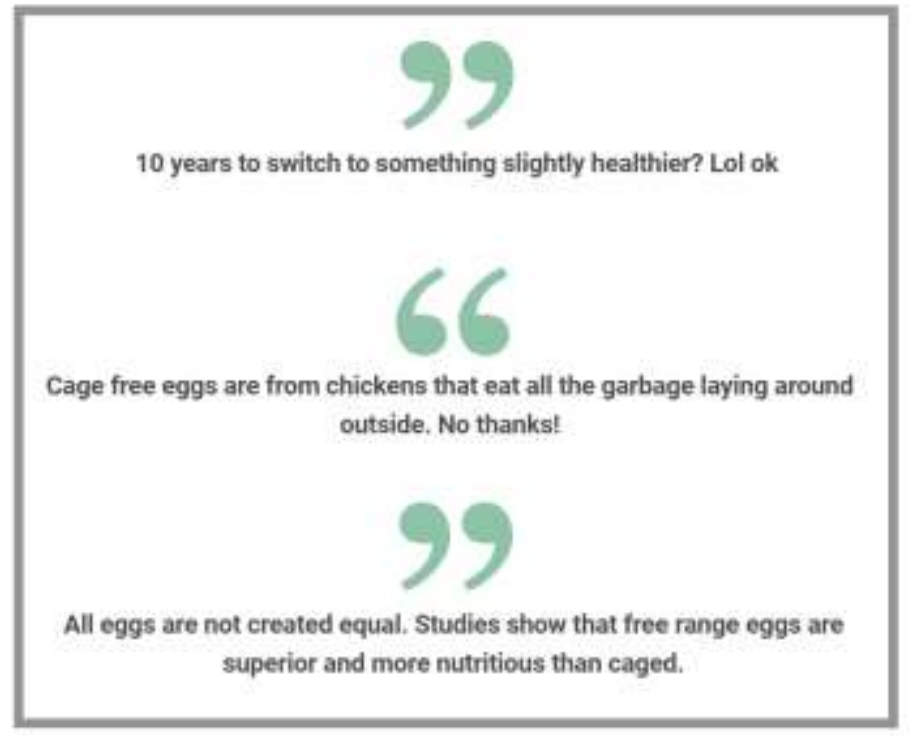

While an interesting point to debate, the results suggest that members of the general public do not spontaneously jump to concerns about restriction of consumer choice. Only one comment (with 0 likes) raised this point at all. In contrast, far more comments mentioned exercising consumer choice by taking their business elsewhere, as discussed in our summary of the Intended Purchase or Consumption Behavior theme. 


\section{faunalytics}

It is possible that this concern will become more prevalent as the number of corporations that aren't using cage-free eggs dwindles, but we expect that by that point cage-free eggs will be the norm and that the lack of choice will therefore be invisible to most consumers.

\section{Cage-Free Hurts Farmers}

Farmers' advocacy groups commonly express concerns or anger about the transition hurting farmers, so we included a coding category to look for similar sentiments in the general public. However, only one comment (with 0 likes) raised this issue, suggesting that this isn't a point the public tends to raise spontaneously (though they may in response to farmers' advocates).

\section{Additional Themes}

\section{Wants More Change From Corporation In Other Areas}

Some commenters (62 comments with 54 likes) took the opportunity to ask for changes unrelated to animal welfare. These were generally health-related, as shown in the examples in Figure 17. The prevalence of health-related requests in this theme suggests that many members of the public do not distinguish between animal welfare improvements and health improvements.
Figure 17. Comment Examples: Demands For More Change From Corporation In Other Areas.

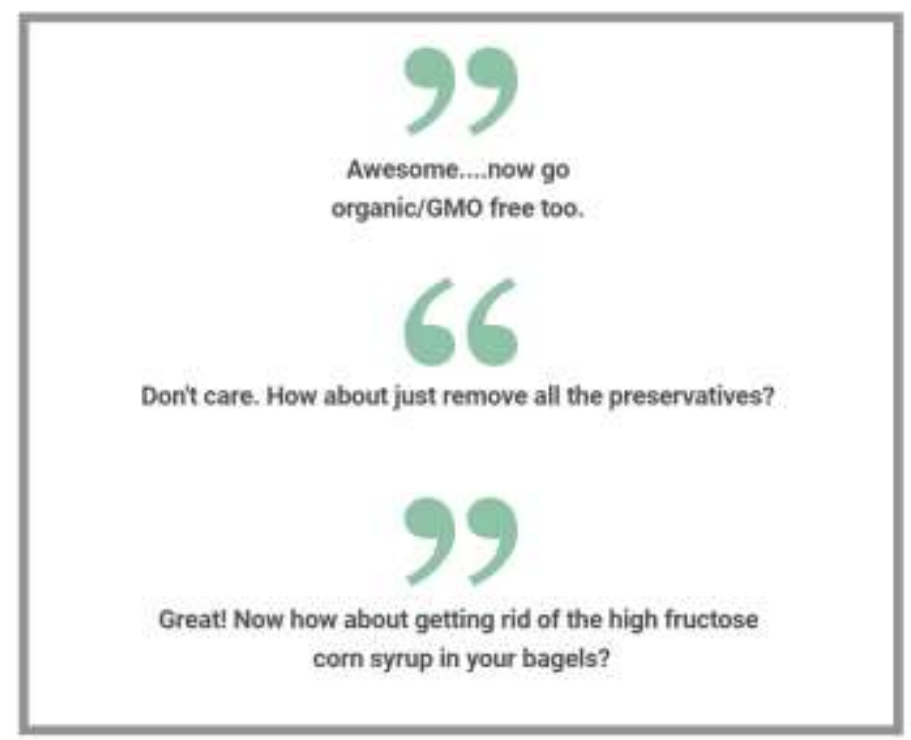




\section{faunalytics}

\section{Information-Sharing}

About $10 \%$ of comments (166 comments with 133 likes) were attempts to educate other readers about issues around cage-free eggs. These attempts covered a wide range of topics: the meaning of terms like 'cage free,' supply chain logistics, chicken sentience, and personal experiences with backyard chickens. Some were more accurate or backed up by evidence than others, but we coded any attempt to share knowledge or experience relevant to cage-free eggs in this category.

Perhaps unsurprisingly, the majority of info-sharing comments (59\%) were made in reply to other commenters. This is a very high proportion because replies made up only $19 \%$ of the whole dataset.

\section{Excluded Themes}

Comments were coded into several additional themes, but these are not particularly meaningful so we don't discuss them in detail. Namely:

- Many respondents (164 comments, 138 likes) expressed off-topic negativity about the corporation (e.g., "Wow. What next, real meat in their burgers."). These comments are included in the sentiment analysis earlier in this text, but irrelevant themes are not described further.

- 68 comments were coded as "shares" - a comment tagging a person with their name.

- 12 comments were coded as corporate responses - comments that appeared to come from the corporation's Facebook account (e.g., "Thank you, Mark!" in response to a positive comment).

- 68 comments were coded simply as "other" (on-topic and understandable but not codeable into one of the other categories).

- Finally, 622 comments ( $28 \%$ of the original dataset) were categorized as uncodeable in a meaningful way: "insubstantial or uninterpretable," per the coding scheme. These comments included advertising spam (e.g., a link to an unrelated product), off-topic or tangential remarks (e.g., "makes me think of my grandpa, Franco"), jokes (e.g., "Josh 


\section{faunalytics}

Rosen is a caged egg"), and some where there simply wasn't enough context for coders to interpret the commenter's intentions (e.g., "Ugh I love this place").

The final point shows that a substantial proportion of comments were excluded as uncodeable. However, unlike a higher failure rate on an attention check, this does not dilute the interpretation of the remaining comments. It simply highlights the "anything goes" nature of social media. The one exception is in the interpretation of apathy, as described in the Apathy: Who Cares? section earlier in this text.

\section{Limitations Of Results}

\section{Representation Of Corporations And General Public}

Facebook was chosen as the platform for this study because it is used by such a large proportion of the adult American population. Even so, it does not capture the entire population, and the proportion of people who read and choose to comment on stories is smaller still. Thus, this study cannot be said to produce results that are generalizable to all potential egg consumers in the US.

Instead, this dataset is naturalistic, representing the corporations that the media tends to focus on and the people who tend to comment. Thus, it naturally overrepresents larger, more visible corporations (e.g., McDonald's) and comments from more outspoken or motivated people. So, while not representative of the full population, it is better at representing the kind of public discourse that occurs. There are pros and cons to either approach, but this one allows natural responses to float to the surface without the research process itself influencing the responses (as it might in the case of survey questions).

It is difficult to quantify the ways in which the commenters differ from the general public, but Table $\mathrm{S} 1$ in the Supplementary Materials section shows how the corporations in our sample differ from the full list of those who had made cage-free commitments.

\section{Overrepresentation Of Animal Advocates?}

In the early stages of this project, it was pointed out to us that animal advocates might be overrepresented in the dataset because lobbying efforts often involved encouraging advocates to flood companies' social media accounts with messages.

To address this possibility, we attempted to examine the frequency of animal advocates, vegans, or sympathizers in our dataset. Ideally, we would be able to flag each commenter as an advocate or not and conduct analyses with and without them, but Facebook's system for protecting the identities of its users prevents scraping commenter IDs or profile information. Instead, we manually examined public profiles for commenters on a random subset of posts-three direct corporate announcements and three news stories announcing commitments.

Commenters were flagged as likely animal advocates if they met any of the following criteria:

1. They have clear information in their profile like "animal advocate" or "works at: The Humane League"; 


\section{faunalytics}

2. They have liked or followed at least one animal advocacy organization other than local shelters (e.g., PETA, The Humane League, Vegan Outreach); or

3. They have liked more than one fan page about veganism/vegan products (Beyond Meat, Vegan.com etc.)

Overall, 45 of 555 commenters (8\%) whose profiles were publicly visible were identified as likely animal advocates using these criteria. Although not a perfect system, this provides reasonable evidence that our analysis is not unduly biased by an overrepresentation of animal advocates among the commenters.

\section{Comparative Analysis: Cage-Free Vs. Comparison Article Comments}

Author Note: Analysis and write-up of this section of the report were performed by Faunalytics volunteer Alison Lenton, PhD.

To add nuance to our understanding of the meaning of the comments on articles about corporate cage-free commitments, we used a software program called Linguistic Inquiry and Word Count (LIWC) to compare them to a set of non-commitment-related articles matched for source and date (Pennebaker, Booth, Boyd, \& Francis, 2015).

LIWC automatically analyzes the content of text documents. For a given sample of text, it counts the number of words (or symbols) and also compares each word (or symbol) to those in more than 80 word categories for which it possesses dictionaries (e.g., themes such as family, emotions, visual perception, and biological functions; themes related to work, home, money, and death; and parts of grammar, such as first-person singular pronouns, prepositions, and adjectives). LIWC can then tell you what percentage of the words in the text sample belong to each category.

\section{Research Questions}

We pre-registered interest in examining whether comments made about cage-free articles might differ from other articles with respect to the following LIWC categories:

- Positive Emotion Words (e.g., love, nice, sweet)

- Negative Emotion Words (e.g., hurt, ugly, nasty)

- Swear Words (e.g., fuck, damn, shit)

- Exclamation Marks (i.e., !)

- Question Marks (i.e., ?)

- Interrogatives (e.g., when, where, how)

In other words, we wondered how people would react to announcements of a company's intention to use eggs from cage-free hens: Would they express more or less positive emotion than they 


\section{faunalytics}

would to any other social media article? More or less negative emotion? How often would they use swear words, exclamation marks (as an indicator of passion/intensity), and question marks or interrogatives (as indicators of questions about the company's stated intentions/commitment)?

These questions are similar to those addressed by the thematic analysis, but they have the added benefit of being compared against articles on other topics that are also posted on social media. This provides context to the results so that we can see, for example, whether the degree of positivity/negativity in the comments is just how people respond to anything on social media.

\section{Emotional Reactions}

Cage-free article comments contained more positive emotion words and fewer negative emotion words than comments on the comparison articles. In other words, people were relatively more approving of the cage-free announcements than they were of the comparison articles. For example, LIWC identified more comments containing words such as yay, awesome, good, wow, $\mathrm{cool}$, and great in response to the cage-free commitment articles. Conversely, the comparison articles yielded comments that were more likely to contain words such as lazy, dislike, pathetic, stupid, horrible, and ridiculous. See Figure 19 below.

Thus, reactions to the cage-free announcements were quite mixed, but these results show that any article will receive both positive and negative reactions, and the cage-free announcements were received more positively and less negatively on average. Overall, the response to corporate animal welfare commitments is encouraging. 


\section{faunalytics}

Figure 19. Emotions Expressed In Response To Cage-Free Versus Comparison Articles.

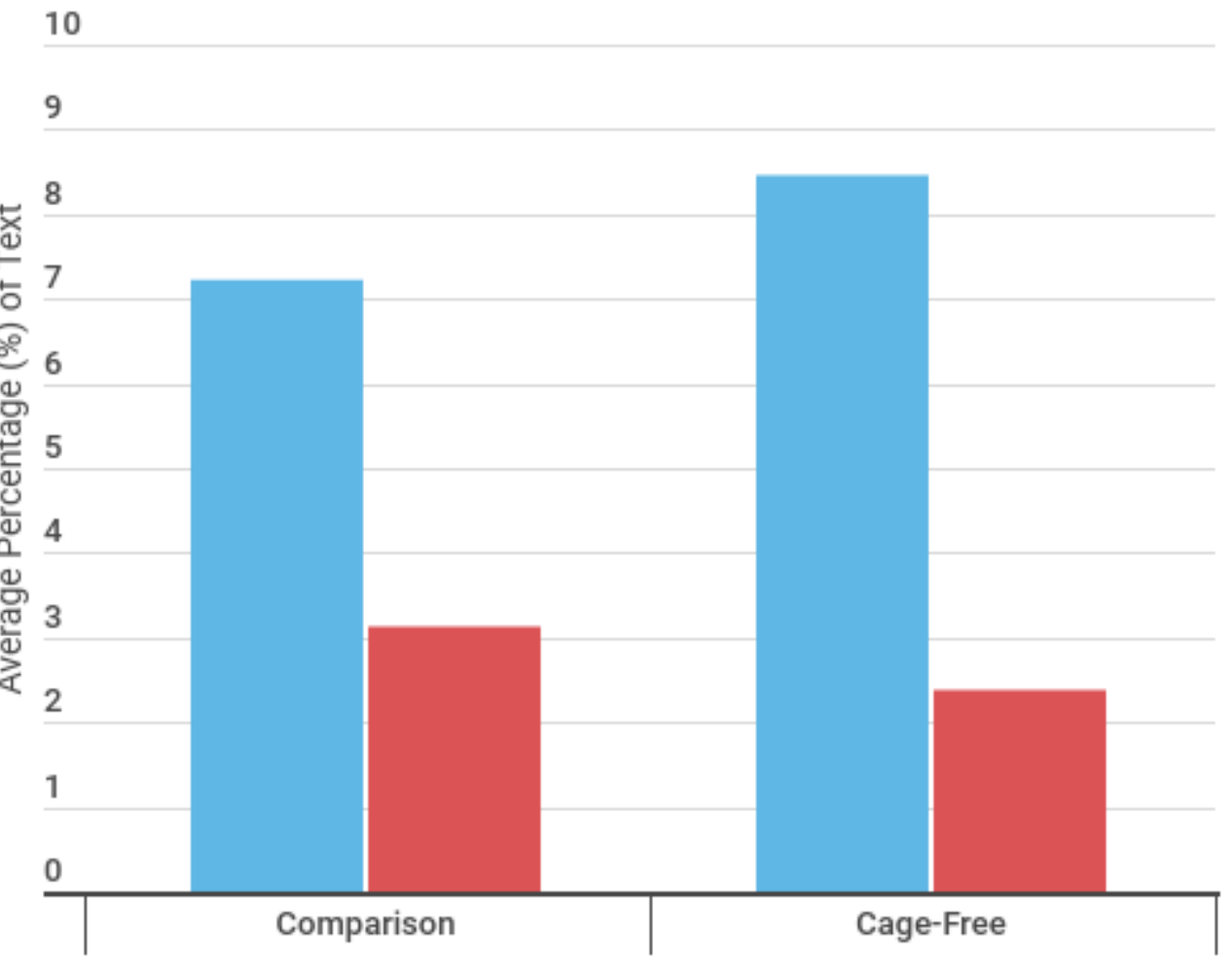

Type of Article

Positive Emotion

Negative Emotion

\section{Questions}

Cage-free article comments were more likely to include interrogative words (e.g., who, why, when) and question marks than were comparison articles. Illustrative comments on the cage-free articles include: Why wait?, Why so long?, Why not now? Why wait 10 years???, and What is the holdup!!!???

This result mirrors the thematic analysis, which found that criticism or questioning of the timeline was the most common response.

\section{Swearing And Exclamations}

Cage-free article comments did not differ from comments on comparative articles with respect to the use of swear words or exclamation marks. The frequency of the use of swear words was quite low in both types of articles, and people were no more (or less) likely to use exclamation points for emphasis. 


\section{faunalytics}

We interpret these findings as meaning that people were no more passionate, on average, about the cage-free egg announcements than the comparison articles. This, in conjunction with a large number of apathetic responses in the thematic analysis, suggests that the general public is not riled up about the issue of animal welfare reform.

\section{Exploratory Analyses: Other Differences Between The Cage-Free And Comparison Articles}

We also explored whether the comments on the cage-free and comparison articles differed in other ways.

Methodological note: Because we did not pre-register the exploratory analyses described below, we adopted a more stringent rule for determining whether the difference (if any) between the articles was significant or not. Specifically, we used Bonferroni correction, dividing the standard alpha criterion of $p=.05$ by the number of exploratory tests $(\mathrm{n}=15)$ to achieve a new threshold of $p=.0033)$.

\section{They Versus I}

Comments on cage-free articles were more likely than those on comparison articles to use Theyrelated pronouns (e.g., they, their, they'd) and less likely to use I-related pronouns (e.g., I, me, mine).

This result suggests that articles about cage-free reform make commenters think more about others ('they' is usually the company, but sometimes chickens or eggs) and less about themselves than other articles. Although being less self-focused sounds like a good thing, in this case it may reflect a tendency for commenters not to see any implication of animal welfare reform for their own lives or behavior.

\section{Money}

Comments on cage-free articles were also more likely than those on comparison articles to use words referring to Money (e.g., audit, cash, owe). Example comments include: "Cheap marketing," and "Cage-free eggs = higher prices to consumer." Although not all comments in this category refer to the price of eggs, this generally supports the idea that the public may be concerned about prices going up.

\section{Causation}

Comments on cage-free articles were more likely than those on comparison articles to use words indicative of Causation (e.g., why, because, effect). However, this difference appeared to be driven largely by the word why, which was also included in the Questions category above. It is likely due to questions about the timeline. 


\section{Death, Anger, Sadness, And Other Non-Significant Differences}

The sections above describe all the themes where significant differences between cage-free and comparison articles emerged.

One might have expected to find more comments on the cage-free (versus comparison) articles related to Death (of chicks), for example, or to find more comments reflecting Anger (e.g., perhaps at the delay of implementation) or Sadness (e.g., perhaps at the past state of affairs), but these exploratory analyses indicated that commenters on both types of articles were equally likely to use words related to these concepts.

There was also no difference in the use of words related to Anxiety, Insight (e.g., think, know, consider), Discrepancies (e.g., should, would, could), Comparisons (e.g., better, worse, tiniest, biggest), Certainty (e.g., always, never), Tentative (e.g., maybe, perhaps, guess), and Assent (e.g., agree, ok, yes). 


\section{faunalytics}

\section{Conclusions}

\section{Advocates Should Continue To Emphasize Corporate Lobbying}

The results of this study support continued lobbying efforts directed at corporations. It is important to note that this was far from a foregone conclusion. We had several research questions that might have suggested the opposite, but none were supported by the data. None of the results suggest any cause for concern about lobbying efforts.

First, our comparative analysis showed that although reactions to the cage-free announcements were a mix of critical, enthusiastic, and apathetic, they were actually more positive on average than social media articles on other topics. In other words, any article will receive both positive and negative reactions, and the cage-free announcements had a higher proportion of positive reactions and a lower proportion of negative ones than other articles. Overall, response to corporate animal welfare commitments is encouraging.

Though criticisms of the welfare implications of the change were common, these criticisms rarely translated into intended behavior-people saying that they would not eat at the restaurant again, which would be corporations' primary concern.

Apathy was frequent but is not cause for concern. In fact, it suggests that advocates should continue to emphasize corporate lobbying efforts because apathetic individuals are unlikely to resist further corporate lobbying efforts and would provide more challenging targets for direct behavioral intervention.

One concern that is sometimes raised about the incremental approach to improving animal welfare is that it may inspire complacency: the idea that making this one small change is enough and no further action is needed. This concern was somewhat rejected by this study, in that almost no one openly expressed complacency.

Defined more broadly, passive complacency might be implied by the majority of positive responses not calling for further action. However, passive complacency does not suggest that these positive responders would be resistant to further lobbying efforts. These results are somewhat ambiguous but speak more against the idea of incremental change causing complacency than for it.

\section{Corporations Should Not Fear Response To Animal Welfare Improvements}

Only 10 of the 75 restaurants in our full list had announced their cage-free commitments on their Facebook pages, as described in the Supplementary Materials section. This may suggest that most corporations preferred to keep their commitments out of the public eye-perhaps over concern about public reaction. However, the results of this study should reassure corporations about future commitments.

First, response to corporate announcements of cage-free reform was more positive than response to social media articles on other topics, suggesting that animal welfare reform is a net positive with the general public. 


\section{faunalytics}

In addition, few people indicated that they would take their business elsewhere, suggesting that the critical reactions from a subset of the public should not be taken as damaging. For the most part, people who said that they would not eat at these restaurants were people who already avoided them. The one caveat is that this question should be re-evaluated if significant costs will be passed on to the consumer, because there were quite a few comments on the cost theme.

Finally, it is important to note the complete lack of concern in these comments about restriction of consumer choice. If corporations are concerned about that idea, these findings suggest that they need not be. A key benefit of a naturalistic data collection like this is that it allows us to see which concerns rise to the surface unprompted by researchers-and restriction of consumer choice does not.

Making a public commitment is a well-known way of ensuring follow-through (e.g. Lokhorst, Werner, Staats, van Dijk, \& Gale, 2011), so we hope that these results will encourage more openness from corporations in the future.

\section{Public Interest Pertaining To Animal Welfare Reform}

The issues that concern advocates, corporations, and economists are not necessarily the same ones that concern the general public.

In terms of implications for themselves, people were most concerned about the potential higher cost of cage-free eggs. This is a topic that warrants study of purchase behavior as any increased costs are passed on to the consumer.

The next most common concern was the aesthetics of cage-free eggs compared with traditional caged eggs: taste, texture, color, and so on. A small group of commenters believed that cagefree eggs are aesthetically better.

Few commenters were concerned about the health and safety of cage-free eggs, and comments on this theme were balanced between people claiming that cage-free eggs are healthier or safer and people claiming that they are less healthy or safe.

Finally, concerns about the restriction of consumer choice or the transition hurting farmers were vanishingly rare. We looked specifically for these concerns because they are brought up in some debates about corporate campaigns, but almost no one in the general public commented about these issues.

\section{Public Understanding Of Animal Advocates' Role In Reform}

Comments about animal advocates were relatively uncommon, suggesting that advocates' role in these reforms is not well-known. Most references that were made were negative, so keeping that role quiet may be the best strategy. For comparison, corporations received more than ten times as much positive or negative commentary as advocates, advocacy groups, and vegans.

This suggests that, as long as the media doesn't play up advocates' role in obtaining corporate commitments, it doesn't come to mind for most people. Given that the most common response when it did come to mind was negative, this is likely a good thing and something to continue. 


\section{faunalytics}

\section{Public Understanding Of Issues}

Finally, it may be worth noting that the general public has a poor understanding of supply chain conversion and tends to be concerned about the 'wrong' things. Full conversion is effortful, with many steps. A long timeframe for the process is therefore reasonable, particularly for larger corporations that use a lot of eggs. For that reason, skepticism about follow-through might be justified because of the effort and number of steps required to achieve full conversion. However, the public shows the opposite pattern, tending to be skeptical about the need for a long timeline but with few comments expressing concern about follow-through. This suggests a misunderstanding or lack of consideration about what is involved in reform. 


\section{faunalytics}

\section{Supplementary Materials}

\section{Detailed Method}

\section{Pre-Registration}

In accordance with best practices, this study was pre-registered with the Open Science Framework before the coders reviewed the data. The pre-registration detailed the study design and analysis plan. It also included the specific deductive codes used, which were developed from our research questions.

\section{Data Set Inclusion Criteria}

Our data set comprised publicly available comments on Facebook in response to corporate announcements of commitments to switch to cage-free eggs. Facebook was selected over other social media platforms because it has several times the amount of market penetration: Approximately 8 in 10 U.S. adults with internet access use it (Pew Internet, 2016).

Based on data available from CageFreeFuture.com, www.ciwf.com/eggtrack and welfarecommitments.com, we selected all restaurant/fast food corporations that specified a date by which they commit to using cage-free eggs. To examine the representation of different types of these corporations, we have sorted the full list from these three sites into categories based on their size (1-999 U.S. locations / 1,000-9,999 U.S. locations / 10,000+ U.S. locations) and type (limited-service / full-service). This list is provided in Table S1.

We then investigated the availability of Facebook posts about each corporation's cage-free commitment, restricting inclusion to posts from either the main account of the corporation itself or from U.S. news sources. That is, posts from Facebook groups, public figures, and individuals were excluded. These inclusion criteria encompass a wide range of leanings and biases, while limiting posts to a manageable number.

We included all posts that met the above inclusion criteria, with the exception of posts pertaining to McDonald's. For McDonald's, we restricted the total number of posts to 10 (the same as the most available for any other corporation) to avoid skewing the dataset, as there were dozens of McDonald's posts to choose from.

The full dataset includes 2,239 comments pertaining to 22 restaurant corporations. The comments were drawn from 10 Facebook announcements by corporations themselves and 53 news stories posted publicly to social media. The list of posts is provided in Table S2.

\section{Data Collection}

The content of the 63 selected posts were saved, along with data about post date, number of likes, and number of shares. All comments on each post were downloaded by an automated 


\section{faunalytics}

scraping tool (with Facebook's approval), along with information about the number of likes per comment. Comments that are made in response to another comment were indicated.

\section{Thematic Content Coding}

The principal investigator (PI) and team developed a coding scheme using a combination of deductive coding, in which code categories are determined by theory and hypotheses, and inductive coding, in which code categories are generated based on coders' reading and interpretation of the underlying conceptual meaning of the data.

The development of the coding scheme and coding the data proceeded as follows:

1. Faunalytics staff and volunteers generated a number of hypotheses about possible responses to a corporate commitment to cage-free eggs. The PI then defined deductive code categories based on these hypotheses.

2. The deductive code categories were then revised based on peer review by other animal advocacy researchers. The final deductive code categories were included in the preregistration document. Most of these codes pertained to our broad research questions. Namely, whether there was evidence of impact on: attitudes about the corporation, attitudes about animal welfare, attitudes about animal advocates/advocacy, and intended behavior.

3. Pre-registration occurred at this step, prior to coders reading the comments.

4. All members of the coding team (PI and coders) read all the comments to get an initial feel or impression of the data. The team did not create any inductive codes during this step.

5. After the team read through all the comments, the coders reviewed $20 \%$ of the comments to generate an initial set of inductive code categories. Each of the coders independently developed codes to capture the meaning of the comments.

6. The PI and coders reviewed their proposed codes together and reached agreement on creation of the inductive codes, the code names, and their meanings. They also discussed and agreed on the application of the deductive codes. Through this collaborative process an initial foundational code scheme was generated.

7. Beginning with the foundational coding scheme, the coders then went through several iterations of coding and revising the coding scheme until both were satisfied with their understanding of the codes. Disagreements were resolved by the PI.

8. At this point, the coders proceeded to independently code an additional $20 \%$ of the comments using the revised coding scheme. The PI performed an inter-rater reliability check following completion of this coding. The average kappa for the substantive codes (numbers $1-21$ on the coding scheme) was $80 \%$, the pre-registered target value (per McHugh, 2012). The average for the full set (including irrelevant and "other" codes, numbers $95-100)$, was $75 \%$ due to a lower average (62\%) for the non-substantive codes. Disagreements were resolved by the PI.

9. Based on the strong agreement for the substantive codes, the PI made the decision to split up the remaining $60 \%$ of comments between the members of the coding team. Small revisions were made to the non-substantive codes (including collapsing two categories) to 


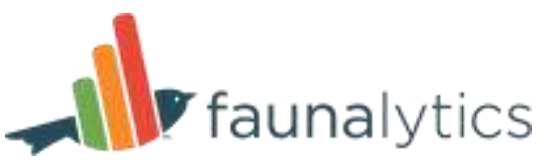

improve coders' understanding, and the coding scheme was finalized. Coding of the remaining comments then occurred.

Table S1. Prevalence Of Corporations By Size And Type.

\begin{tabular}{|c|c|c|c|}
\hline Size/Type & Corporations & $\begin{array}{c}\text { Number }(\%) \text { in } \\
\text { Full } \\
\text { List }\end{array}$ & $\begin{array}{l}\text { Number } \\
(\%) \text { in } \\
\text { Sample }\end{array}$ \\
\hline $\begin{array}{l}\text { Large, Limited } \\
\text { Service }\end{array}$ & $\begin{array}{l}\text { 7-Eleven } \\
\text { Burger King } \\
\text { Dunkin' Donuts* } \\
\text { McDonalds* } \\
\text { Starbucks* } \\
\text { Subway* }\end{array}$ & $6(8 \%)$ & $4(18 \%)$ \\
\hline $\begin{array}{l}\text { Medium, Limited } \\
\text { Service: }\end{array}$ & $\begin{array}{l}\text { AgW } \\
\text { Arby's } \\
\text { Baskin-Robbins } \\
\text { Carl's Jr. } \\
\text { Chick-Fil-A } \\
\text { Chipotle: } \\
\text { Dairy Queen* } \\
\text { Einstein Bros: Bagels* } \\
\text { Hardee's } \\
\text { Jack in the Box } \\
\text { Krispy Kreme } \\
\text { Panda Express: } \\
\text { Papa John's } \\
\text { Panera Bread* } \\
\text { Quiznos: } \\
\text { Sonic Drive-In } \\
\text { Speedway } \\
\text { Taco Bell* } \\
\text { Tim Hortons } \\
\text { Wendy's* }\end{array}$ & $20(27 \%)$ & $5(23 \%)$ \\
\hline $\begin{array}{l}\text { Medium, Full } \\
\text { Service }\end{array}$ & $\begin{array}{l}\text { Applebee's } \\
\text { Chili's } \\
\text { Denny's* } \\
\text { IHOP } \\
\text { Outback Steakhouse* } \\
\text { TGI Friday's }\end{array}$ & $6(8 \%)$ & $2(9 \%)$ \\
\hline
\end{tabular}




\section{faunalytics}

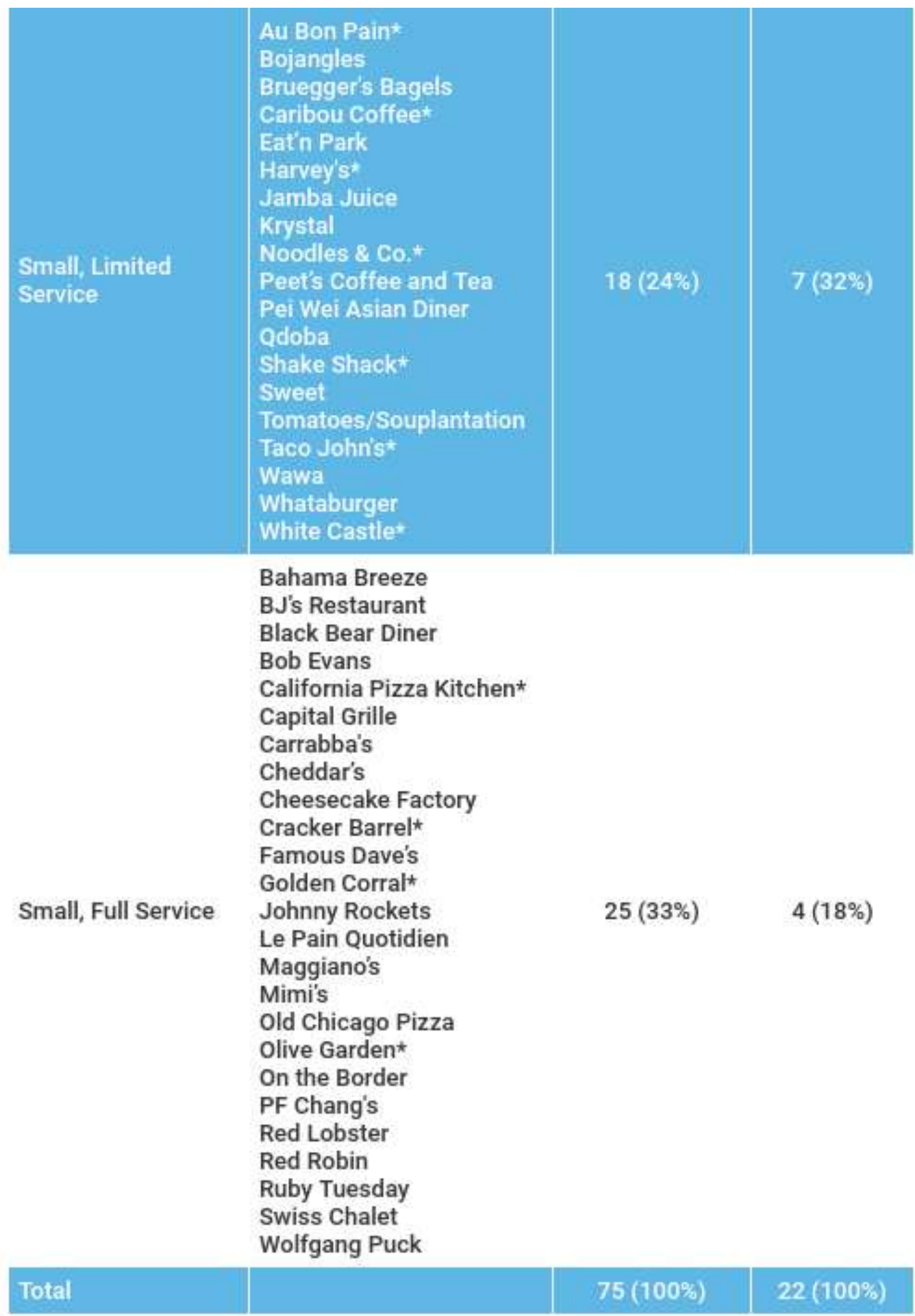

Notes. Small $=1$ - 999 US locations; medium $=1,000-9,999$ US locations; large $=10,000+$ US locations. Corporations with an asterisk are included in our sample. 
Table S2. Selected Posts Included In Analysis

\begin{tabular}{|c|c|c|c|c|}
\hline Corporation & Size & Service & Post Source & Comments \\
\hline Subway & large & $\begin{array}{l}\text { limited } \\
\text { service }\end{array}$ & Fortune Magazine & 23 \\
\hline Subway & large & $\begin{array}{l}\text { limited } \\
\text { service }\end{array}$ & The Consumerist & 12 \\
\hline Starbucks & large & $\begin{array}{l}\text { limited } \\
\text { service }\end{array}$ & Fortune Magazine & 6 \\
\hline Starbucks & large & $\begin{array}{l}\text { limited } \\
\text { service }\end{array}$ & New York Magazine. & 6 \\
\hline Dunkin' Donuts & large & $\begin{array}{l}\text { limited } \\
\text { service }\end{array}$ & Fortune Magazine & 3 \\
\hline Dunkin' Donuts & large & $\begin{array}{l}\text { limited } \\
\text { service }\end{array}$ & Chicago Tribune & 11 \\
\hline Dunkin' Donuts & large & $\begin{array}{l}\text { limited } \\
\text { service }\end{array}$ & Huffington Post & 31 \\
\hline Dunkin' Donuts & large & $\begin{array}{l}\text { limited } \\
\text { service }\end{array}$ & $\begin{array}{l}\text { WPTV5 (NBC West } \\
\text { Palm Beach Fl. } \\
\text { Affiliate) }\end{array}$ & 42 \\
\hline Dunkin' Donuts & large & $\begin{array}{l}\text { limited } \\
\text { service }\end{array}$ & The Consumerist & 3 \\
\hline Dunkin' Donuts & large & $\begin{array}{l}\text { limited } \\
\text { service }\end{array}$ & $\begin{array}{l}\text { Boston.com (Boston } \\
\text { Globe Affiliate) }\end{array}$ & 35 \\
\hline Dunkin' Donuts & large & $\begin{array}{l}\text { limited } \\
\text { service }\end{array}$ & Wisconsin Gazette & 5 \\
\hline McDonald's & large & $\begin{array}{l}\text { limited } \\
\text { service }\end{array}$ & $\begin{array}{l}\text { Corporate } \\
\text { announcement }\end{array}$ & 25 \\
\hline McDonald's & large & $\begin{array}{l}\text { limited } \\
\text { service }\end{array}$ & $\begin{array}{l}\text { Christian Science } \\
\text { Monitor }\end{array}$ & 24 \\
\hline McDonald's & large & $\begin{array}{l}\text { limited } \\
\text { service: }\end{array}$ & USA Today & 118 \\
\hline McDonald's & large & $\begin{array}{l}\text { limited } \\
\text { service }\end{array}$ & Consumer Reports & 39 \\
\hline McDonald's & large & $\begin{array}{l}\text { limited } \\
\text { service: }\end{array}$ & Fortune Magazine & 2 \\
\hline McDonald's & large & $\begin{array}{l}\text { limited } \\
\text { service }\end{array}$ & The Gazette & 4 \\
\hline McDonald's & large & $\begin{array}{l}\text { limited } \\
\text { service }\end{array}$ & Spokesman-Review & 18 \\
\hline McDonald's & large & $\begin{array}{l}\text { limited } \\
\text { service }\end{array}$ & MSNBC & 185 \\
\hline McDonald's & large & $\begin{array}{l}\text { limited } \\
\text { service }\end{array}$ & VICE News & 77 \\
\hline McDonald's & large & $\begin{array}{l}\text { limited } \\
\text { service }\end{array}$ & New York Times & 46 \\
\hline
\end{tabular}




\section{-1) faunalytics}

\begin{tabular}{|c|c|c|c|c|}
\hline Denny's & medium & $\begin{array}{l}\text { full } \\
\text { service }\end{array}$ & $\begin{array}{l}\text { Corporate } \\
\text { announcement }\end{array}$ & 36 \\
\hline Denny's & medium & $\begin{array}{l}\text { full } \\
\text { service }\end{array}$ & The Daily Meal & 5 \\
\hline Denny's & medium & $\begin{array}{l}\text { full } \\
\text { service }\end{array}$ & $\begin{array}{l}10 \text { News WTSP (St. } \\
\text { Petersburg FI. CBS } \\
\text { affiliate) }\end{array}$ & 21 \\
\hline $\begin{array}{l}\text { Outback Steakhouse } \\
\text { (Bloomin' Brands) }\end{array}$ & medium & $\begin{array}{l}\text { full } \\
\text { service }\end{array}$ & $\begin{array}{l}\text { Tampa Bay Business } \\
\text { Journal }\end{array}$ & 1 \\
\hline Einstein Bros. Bagels & medium & $\begin{array}{l}\text { limited } \\
\text { service }\end{array}$ & $\begin{array}{l}\text { Corporate } \\
\text { announcement }\end{array}$ & 7 \\
\hline Einstein Bros. Bagels & medium & $\begin{array}{l}\text { limited } \\
\text { service }\end{array}$ & $\begin{array}{l}\text { Earlier corporate } \\
\text { announcement }\end{array}$ & 253 \\
\hline Taco Bell & medium & $\begin{array}{l}\text { limited } \\
\text { service }\end{array}$ & CNNMoney & 12 \\
\hline Taco Bell & medium & $\begin{array}{l}\text { limited } \\
\text { service }\end{array}$ & $\begin{array}{l}\text { NBC } 5 \text { (Plattsburgh, } \\
\text { NY, NBC affiliate) }\end{array}$ & 4 \\
\hline Taco Bell & medium & $\begin{array}{l}\text { limited } \\
\text { service }\end{array}$ & Fox 6 Milwaukee & 16 \\
\hline Taco Bell & medium & $\begin{array}{l}\text { limited } \\
\text { service }\end{array}$ & WSJ & 30 \\
\hline Taco Bell & medium & $\begin{array}{l}\text { limited } \\
\text { service }\end{array}$ & Fortune & 2 \\
\hline Taco Bell & medium & $\begin{array}{l}\text { limited } \\
\text { service }\end{array}$ & Time & 11 \\
\hline Taco Bell & medium & $\begin{array}{l}\text { limited } \\
\text { service }\end{array}$ & FoodBeast & 23 \\
\hline Taco Bell & medium & $\begin{array}{l}\text { limited } \\
\text { service }\end{array}$ & $\begin{array}{l}\text { KSBW (NBC / ABC } \\
\text { Santa Cruz, CA, } \\
\text { affiliate) }\end{array}$ & 13 \\
\hline Wendy's & medium & $\begin{array}{l}\text { limited } \\
\text { service }\end{array}$ & The Consumerist & 4 \\
\hline Wendy's & medium & $\begin{array}{l}\text { limited } \\
\text { service }\end{array}$ & $\begin{array}{l}\text { Columbus Business } \\
\text { First }\end{array}$ & 2 \\
\hline Panera Bread & medium & $\begin{array}{l}\text { limited } \\
\text { service }\end{array}$ & NBC & 663 \\
\hline Panera Bread & medium & $\begin{array}{l}\text { limited } \\
\text { service }\end{array}$ & Chicago Sun-Times & 5 \\
\hline Panera Bread & medium & $\begin{array}{l}\text { limited } \\
\text { service }\end{array}$ & $\begin{array}{l}\text { WSLS } 10 \text { (NBC } \\
\text { affiliate in Virginia) }\end{array}$ & 48 \\
\hline Panera Bread & medium & $\begin{array}{l}\text { limited } \\
\text { service }\end{array}$ & $\begin{array}{l}\text { KOAA } 5 \text { (NBC affiliate } \\
\text { in Colorado) }\end{array}$ & 32 \\
\hline Panera Bread & medium & $\begin{array}{l}\text { limited } \\
\text { service }\end{array}$ & $\begin{array}{l}\text { Fox } 21 \text { News } \\
\text { (Colorado) }\end{array}$ & 3 \\
\hline Panera Bread & medium & $\begin{array}{l}\text { limited } \\
\text { service }\end{array}$ & NBC 10 Philadelphia & 17 \\
\hline Panera Bread & medium & $\begin{array}{l}\text { limited } \\
\text { service }\end{array}$ & $\begin{array}{l}\text { Wish-10 (CW } \\
\text { Indianapolis affiliate, } \\
\text { which is itself an } \\
\text { affiliate of CBS) }\end{array}$ & 42 \\
\hline Panera Bread & medium & $\begin{array}{l}\text { limited } \\
\text { service }\end{array}$ & $\begin{array}{l}\text { KSN } 3 \text { TV (NBC } \\
\text { Wichita, KS, affiliate) }\end{array}$ & 6 \\
\hline
\end{tabular}

5

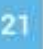
, 


\begin{tabular}{|c|c|c|c|c|}
\hline Panera Bread & medium & $\begin{array}{l}\text { limited } \\
\text { service }\end{array}$ & NBC News Business & 10 \\
\hline Panera Bread & medium & $\begin{array}{l}\text { limited } \\
\text { service }\end{array}$ & $\begin{array}{l}\text { WRAL TV } 5 \text { (NBC } \\
\text { Raleigh, NC, affiliate) }\end{array}$ & 9 \\
\hline Dairy Queen & medium & $\begin{array}{l}\text { limited } \\
\text { service }\end{array}$ & The Daily Meal & 5 \\
\hline Dairy Queen & medium & $\begin{array}{l}\text { limited } \\
\text { service }\end{array}$ & Bring Me the News & 4 \\
\hline Cracker Barrel & small & $\begin{array}{l}\text { full } \\
\text { service: }\end{array}$ & $\begin{array}{l}\text { WBIR (NBC affiliate in } \\
\text { Tennessee) }\end{array}$ & 72 \\
\hline Cracker Barrel & small & $\begin{array}{l}\text { full } \\
\text { service }\end{array}$ & Tennessean & 55 \\
\hline $\begin{array}{l}\text { California Pizza } \\
\text { Kitchen }\end{array}$ & small & $\begin{array}{l}\text { full } \\
\text { service: }\end{array}$ & $\begin{array}{l}\text { Corporate: } \\
\text { announcement: }\end{array}$ & 14 \\
\hline Olive Garden (Darden) & small & $\begin{array}{l}\text { full } \\
\text { service }\end{array}$ & Orlando Sentinel & 1 \\
\hline Golden Corral & small & $\begin{array}{l}\text { full } \\
\text { service: }\end{array}$ & $\begin{array}{l}\text { Corporate: } \\
\text { Announcement }\end{array}$ & 3 \\
\hline Caribou Coffee & small & $\begin{array}{l}\text { limited } \\
\text { service }\end{array}$ & $\begin{array}{l}\text { Corporate } \\
\text { Announcement }\end{array}$ & 20 \\
\hline Noodles \& Co. & small & $\begin{array}{l}\text { limited } \\
\text { service }\end{array}$ & $\begin{array}{l}\text { Corporate: } \\
\text { announcement: }\end{array}$ & 1 \\
\hline White Castle & small & $\begin{array}{l}\text { limited } \\
\text { service }\end{array}$ & CNNMoney & 12 \\
\hline White Castle & small & $\begin{array}{l}\text { limited } \\
\text { service }\end{array}$ & Consumerist & 3 \\
\hline Taco John's & small & $\begin{array}{l}\text { limited } \\
\text { service }\end{array}$ & $\begin{array}{l}\text { Corporate } \\
\text { announcement }\end{array}$ & 42 \\
\hline Taco John's & small & $\begin{array}{l}\text { limited } \\
\text { service }\end{array}$ & $\begin{array}{l}\text { Wyoming Tribune } \\
\text { Eagle }\end{array}$ & 5 \\
\hline Harvey's (Cara) & small & $\begin{array}{l}\text { limited } \\
\text { service }\end{array}$ & Consumerist & 5 \\
\hline Au Bon Pain & small & $\begin{array}{l}\text { limited } \\
\text { service }\end{array}$ & $\begin{array}{l}\text { Corporate: } \\
\text { Announcement }\end{array}$ & 3 \\
\hline Shake Shack & small & $\begin{array}{l}\text { limited } \\
\text { service }\end{array}$ & Eater & 4 \\
\hline
\end{tabular}




\section{Coding Scheme}

This is the final version of the coding scheme used by coders to categorize the comments.

*Inductive codes indicated with an asterisk.

\section{Sentiment Rating Scales}

Coders complete these ratings for every comment.

\begin{tabular}{|c|c|}
\hline \multicolumn{2}{|r|}{ Seale A - Toward Corporation } \\
\hline $5=$ Very positive & $\begin{array}{l}\text { Positive statement, with effusive words or a lot of emphasis - "Thanks } \\
\text { [company]!!! Even more reason to love your product:)" }\end{array}$ \\
\hline $\begin{array}{l}4 \text { = Somewhat } \\
\text { positive }\end{array}$ & $\begin{array}{l}\text { Positive statement, but without effusive words or a lot of emphasis - } \\
\text { "Thank you for taking this very important step, [company)" }\end{array}$ \\
\hline $\begin{array}{l}3=\text { Neutral or } \\
\text { balanced } \\
\text { positive/negative }\end{array}$ & $\begin{array}{l}\text { A statement about the company that isn't clearly positive or negative } \\
\text { OR a comment that includes both - "Very clever, [companyl. But its the } \\
\text { chickens that need to be out of the cages, not the eggs. We're on to } \\
\text { you!" }\end{array}$ \\
\hline $\begin{array}{l}2 \text { = Somewhat } \\
\text { negative }\end{array}$ & $\begin{array}{l}\text { Negative statement, but without hostile wards or a lot of emphasis - "Its } \\
\text { just a PR ploy. Thats it"; Down with lcompany]" }\end{array}$ \\
\hline $1=$ Very negative & $\begin{array}{l}\text { Negative statement with hostile words or a lot of emphasis - "Do } \\
\text { whatever you want to try to reverse your continuing sagging sales. I will } \\
\text { never give your another dime and there are millions who agree with me. } \\
\text { We don't want to consume your nasty contaminated crap. Not now, not } \\
\text { ever:" }\end{array}$ \\
\hline
\end{tabular}

Scale B - Toward Animal Advocates/Vegans/Similar Groups

\begin{tabular}{|c|c|}
\hline $5=$ Very positive & Positive statement, with effusive words or a lot of emphasis \\
\hline $\begin{array}{l}4 \text { - Somewhat } \\
\text { positive }\end{array}$ & Posilive statement, but without effuaive words or a lot of emphasis \\
\hline $\begin{array}{l}3=\text { Neutral or } \\
\text { balanced } \\
\text { positive/negative }\end{array}$ & $\begin{array}{l}\text { A statement about a group that isn't clearly positive or negative OR a } \\
\text { comment that includes both - "nope sorry were omnivores we eat meat } \\
\text { you don't want to that's fine" }\end{array}$ \\
\hline $\begin{array}{l}2=\text { Somewhat } \\
\text { negative }\end{array}$ & $\begin{array}{l}\text { Negative statement, but without hastile words or a lot of emphasis - } \\
\text { "Wow dude you went right off the deep end didfit you. You vegans } \\
\text { always pushing your beliefs onto other's. Yet you could care less about } \\
\text { all the animals who die so you can be vegan and yes hundreds of } \\
\text { thousands of animals die every year to make room for more farming. } \\
\text { Thatis a fact stay vergan all you want ill continue eating meat" }\end{array}$ \\
\hline
\end{tabular}

Negative statement with hostile words or a lot of emphasis - "There are several ways to produce eggs. Cage free is NOT the safest of those $1=$ Very negative choices. It is ridiculous how those animal rights groups have influenced the public by providing articles, especially on social media, that consumer blindly believes. It will hurt America to continue down this path:"

N/A = No sentiment expressed about corporation 


\section{Categorical Codes}

The remainder of the codes are categorical - coders assign each comment to one or more code categories to capture their content.

\section{Additional Attitudes About The Corporation}

Skeptical

about Expresses skepticism about whether the 'commitment' to go cage-free follow- will translate into action. E.g. "Lol it's not going to happen" through

2. Critical of timeline

Mentions the long timeline for switching to cage-free eggs. E.g. "2025. give me a call in 10 years "II"

Other negative

$16 *$ comments about corporation
Negative toward corporation (as expressed on Scale A), but about something specific and irrelevant to cage-free eggs/animal welfare. "Who cares there breakfast still sucks üòçüòçu̇òçüòç"; "Who knew they're eggs were made of eggs?!"

\section{Additional Attitudes About Animal Welfare}

\section{Current Welfare}

\begin{tabular}{l|l|l}
\hline & $\begin{array}{l}\text { Enthusiastic } \\
\text { about } \\
\text { welfare } \\
\text { implications } \\
\text { of change }\end{array}$ & $\begin{array}{l}\text { Mentions that cagefree eggs improve welfare for chickens. E.g. } \\
\text { "Chickens do care if they're in a cage or not" }\end{array}$ \\
\hline
\end{tabular}

Critical of

4 welfare implications don't improve it enough. E.g. "This is meaningless. Just as crowded of change

Mentions that cage-free eggs do not improve welfare for chickens, or and unsanitary. Must be PASTURED chickens" worried about a chicken.

Future Welfare

\begin{tabular}{l|l|l|l} 
Wants more & $\begin{array}{l}\text { Expresses that the corporation needs to make more welfare } \\
\text { change from } \\
\text { improvements. (Code here only if clearly about future action; must go } \\
\text { imation } \\
\text { (welfare) }\end{array}$ & $\begin{array}{l}\text { beyond category } 4 \text {. It's okay to have both.) E.g. "Now if [companyl was } \\
\text { calling for pastured poultry, that would be a real step." }\end{array}$
\end{tabular}

Wants more Expresses that the corporation needs to make more improvements in

17* change from (other)

Wants more

$18 *$ Change (bigger (picture)

Complacent

7 about more change quality). E.g. "I hope a move to compostable paper cups is in their future plans as well"

Expresses a need for more change regarding animal-related issues. but not from this corporation: Other people (e.g., going vegan), other corporations, it should be made into law, etc. E.g. "by 2025 , maybe we will all give up on eggs anyway"

Expresses that this change was enough / more improvements aren't needed. (Code here only if clearly about future action; must go beyond category 5 . It's okay to have both.) 
8 Aesthetically

Mentions aesthetic advantage of cage-free eggs (taste, look, texture, better etc.). E.g. "i like my eggs free range they just are so much better tasting then caged ones"

\begin{tabular}{l|l} 
Not & Mentions there is no aesthetic advantage of cage-free eggs (taste,
\end{tabular}

19* aesthetically better look, texture, etc:) or says they're worse. E.g. "Cage-free eggs taste no different than caged"?

9 Healthier or Mentions health/food safety benefits of cage-free eggs for humans.

Not healthier

Mentions there is no health/food safety benefit of cage-free eggs for eggs. Cage-free is NOT the safest of those choices."

10 Higher cost

Mentions cage-free eggs increasing the cost of food. E.g. "If it makes higher prices to consumer".

Restricts

11 consumer choice

Mentions restrictions on consumers choices, allenating people; or similar.

12 Hurts farmers

Mentions that these changes hurt (small) farmers.

\section{Behavioral Intentions}

Expresses an intention to switch product consumption toward more Increased cage-free eggs, higher-welfare foods (excluding vegan), or similar. Or

13 purchase expresses an intention or willingness to eat more often at that intent particular restaurant. E.g. "I'm delighted to support chains that steward consumer dollars better."

Expresses an intention to switch product consumption to avoid eating

4 purchase intent cage-free eggs, higher-welfare foods, or similar (reactance), Of expresses an intention to eat less often at that particular restaurant:E.g. "no more lcompany] for mel"

No change in purchase intent because commenter never ate at this

21* No purchase restaurant to begin with. - E.g. "whatever, still not eating there" (Also intent code on Scale A for extent of implied negativity - this example would be a 2.)

Intention to reduce egg//

15 animal

product

Expresses an intention to reduce overall egg consumption or general animal product consumption. Do not include here if it references past consumption behaviour change or a call for other people to change behavior. 


\section{Additional Codes}

\begin{tabular}{|l|l} 
Other \\
Sharing knowledge or experience relevant to the topic of cage-free \\
eggs that provides presumed explanatory value to the discussion. \\
E.g., difference between cage-free and free-range, why the timeline \\
is so long, etc. Can double-code with others if it's not completely \\
neutral.This can be implicit in the comment (e.g., "I quit eating \\
sharing \\
shgs a year ago. I have never had more energy or felt better") but \\
stating one's own behavior ("I do X" or "I don't do X").
\end{tabular}

